\title{
Article
}

\section{Operational performance of a novel fast- responsive heat storage/exchanging unit (HSEU) for solar heating systems}

Fan, Yi, Zhao, Xudong, Li, Jing, Cheng, Yuanda, Badiei, Ali, Zhou, Jinzhi, Yu, Min, Li, Guiqiang, Du, Zhenyu, Ji, Jie, Zhu, Zishang, Ma, Xiaoli, Bai, Huifeng and Myers, Steve

Available at http://clok.uclan.ac.uk/38813/

Fan, Yi, Zhao, Xudong, Li, Jing, Cheng, Yuanda, Badiei, Ali ORCID: 0000-00022103-2955, Zhou, Jinzhi, Yu, Min, Li, Guiqiang, Du, Zhenyu et al (2020)

Operational performance of a novel fast-responsive heat storage/exchanging unit (HSEU) for solar heating systems. Renewable Energy, 151 . pp. 137-151. ISSN 0960-1481

It is advisable to refer to the publisher's version if you intend to cite from the work. http://dx.doi.org/10.1016/j.renene.2019.11.007

For more information about UCLan's research in this area go to

http://www.uclan.ac.uk/researchgroups/ and search for <name of research Group>.

For information about Research generally at UCLan please go to http://www.uclan.ac.uk/research/

All outputs in CLoK are protected by Intellectual Property Rights law, including Copyright law. Copyright, IPR and Moral Rights for the works on this site are retained by the individual authors and/or other copyright owners. Terms and conditions for use of this material are defined in the policies page. 


\section{Journal Pre-proof}

Operational performance of a novel fast-responsive heat storage/exchanging unit (HSEU) for solar heating systems

Yi Fan, Xudong Zhao, Jing Li, Yuanda Cheng, Ali Badiei, Jinzhi Zhou, Min Yu,

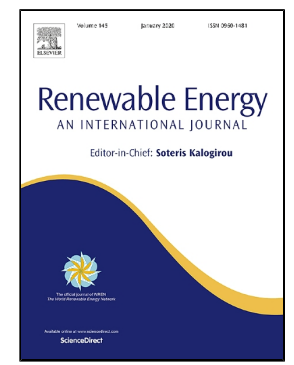
Guiqiang Li, Zhenyu Du, Jie Ji, Zishang Zhu, Xiaoli Ma, Huifeng Bai, Steve Myers

PII: S0960-1481(19)31682-9

DOI: https://doi.org/10.1016/j.renene.2019.11.007

Reference: RENE 12554

To appear in: Renewable Energy

Received Date: 10 April 2019

Accepted Date: 02 November 2019

Please cite this article as: Yi Fan, Xudong Zhao, Jing Li, Yuanda Cheng, Ali Badiei, Jinzhi Zhou, Min Yu, Guiqiang Li, Zhenyu Du, Jie Ji, Zishang Zhu, Xiaoli Ma, Huifeng Bai, Steve Myers, Operational performance of a novel fast-responsive heat storage/exchanging unit (HSEU) for solar heating systems, Renewable Energy (2019), https://doi.org/10.1016/j.renene.2019.11.007

This is a PDF file of an article that has undergone enhancements after acceptance, such as the addition of a cover page and metadata, and formatting for readability, but it is not yet the definitive version of record. This version will undergo additional copyediting, typesetting and review before it is published in its final form, but we are providing this version to give early visibility of the article. Please note that, during the production process, errors may be discovered which could affect the content, and all legal disclaimers that apply to the journal pertain.

(C) 2019 Published by Elsevier. 


\title{
Operational performance of a novel fast-responsive heat storage/exchanging unit (HSEU) for solar heating systems
}

Yi Fan ${ }^{\mathrm{a}}$, Xudong Zhao ${ }^{\mathrm{a} *}$, Jing Li a**, Yuanda Cheng ${ }^{\mathrm{b}}$, Ali Badiei ${ }^{\mathrm{a}}$, Jinzhi Zhou ${ }^{\mathrm{a}}$, Min Yu $\mathrm{u}^{\mathrm{a}}$ Guiqiang Li ${ }^{\mathrm{a}}$, Zhenyu Du${ }^{\mathrm{b}}$, Jie Jic ${ }^{\mathrm{c}}$, Zishang Zhu ${ }^{\mathrm{a}}$, Xiaoli Ma ${ }^{\mathrm{a}}$, Huifeng Baid ${ }^{\mathrm{d}}$, Steve Myers ${ }^{\mathrm{a}}$

\author{
a School of Engineering and Computer Science, University of Hull, Hull, HU6 7RX, UK \\ ${ }^{b}$ College of Environmental Science and Engineering, Taiyuan University of Technology, \\ 030024, China
}

'Department of Thermal Science and Energy Engineering, University of Science and Technology of China, 230026, China

dShanxi Zhonglv Environmental Protection Group Co., LTD, China

*Corresponding author. Tel.: +44-01482466684, Email: xudong.zhao@hull.ac.uk

** Corresponding author. Tel.: +86-551-63607517, Email: lijing83@ustc.edu.cn

\begin{abstract}
In order for a solar heating system to provide heat immediately after sunrise, a fast response is needed to the heat demand of a serviced space. The majority of existing solar heating systems have a slow response time due to the large volume of water stored in the heat storage/exchanger unit (HSEU). This leads to a slow heat delivery cycle, which results in discomfort for the occupants and thus creates a huge barrier to the wide deployment of solar heating systems. To overcome this critical issue, a novel interactive heat storage/exchanging unit (HSEU) employing a double-tank configuration was developed. Unlike conventional HSEUs, which have a single tank acting as the heat storage and exchanging unit, the new HSEU is comprised of a small tank for heat exchange combined with a large tank for heat storage. The small tank enables fast transfer of solar heat to the heating loop fluid without having to heat up the large volume of water in the entire HSEU tank, whilst the large tank is used to store and exchange heat between itself and the small tank using a temperature-oriented control mechanism. To test the proposed design, the heat transfer between the first (solar loop) and second (heating loop) fluids, the heat and mass transfer between the small and large tank and the associated operational strategy were investigated experimentally and theoretically for comparison. A conventional single tank HSEU requires around 120 minutes to deliver heat to a served space, whilst the new interactive double-tank HSEU can provide heat to the served
\end{abstract}


space in around 20 minutes, thus creating a heating system which can respond significantly faster than traditional systems. The investigation of the heat exchange effect between the solar and heating loop fluids showed that the new HSEU achieved a convective heat transfer coefficient of as high as $391 \mathrm{~W} / \mathrm{m}^{2} \cdot \mathrm{K}$, which is $551 \%$ higher than that of a conventional tank. As a result, the solar thermal efficiency of the solar panel-array in the new HSEU based system was increased by $7.5 \%$ compared to conventional HSEU based systems.

Key words: Fast response; Heat storage/exchanging unit; Response time; Space heating; Solar thermal efficiency; Heat transfer coefficient

\section{Nomenclature}

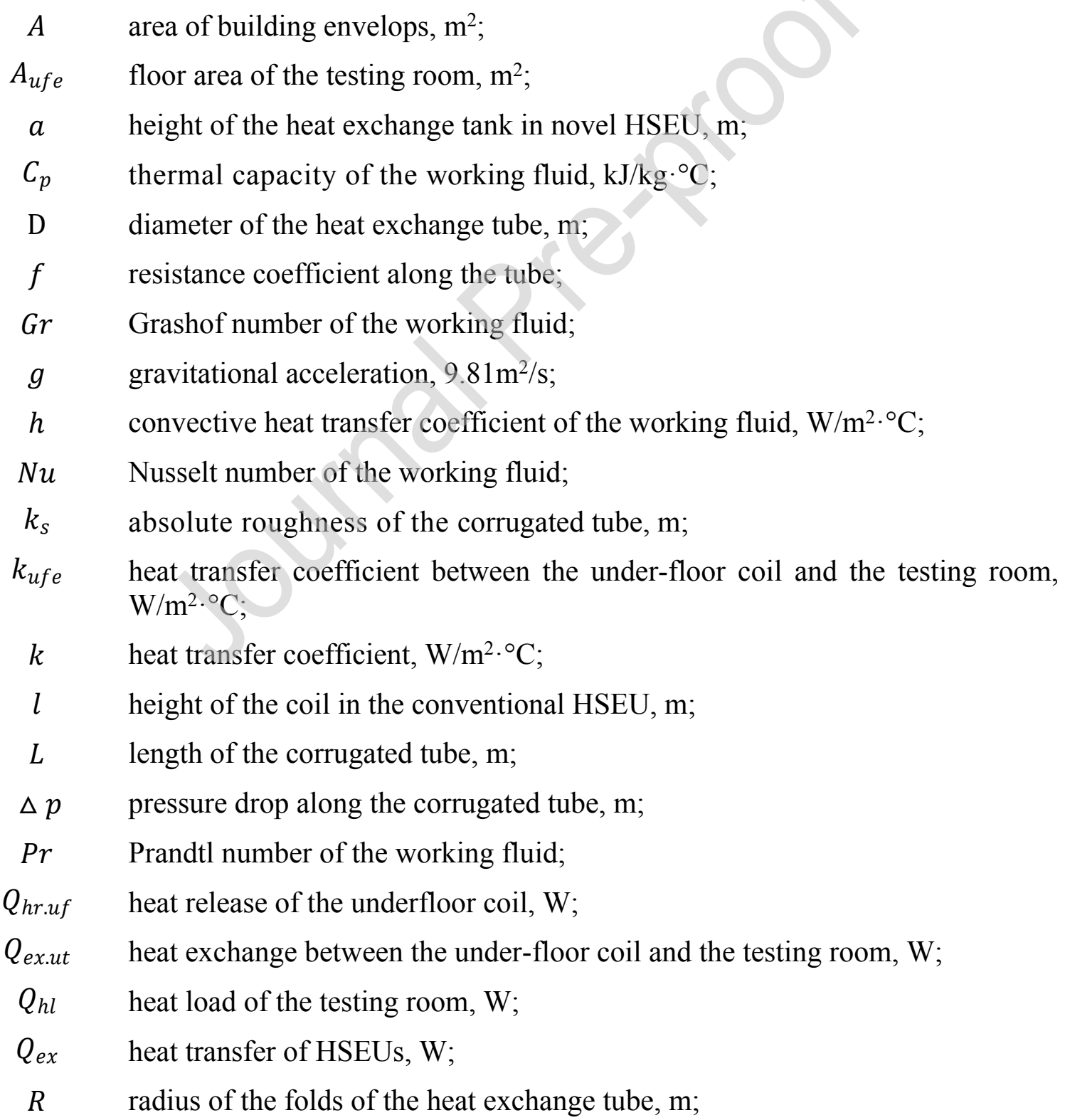


Re Reynolds number of the working fluid;

$S \quad$ area per meter heat exchange tube or the solar thermal panels, $\mathrm{m}^{2} / \mathrm{m}$;

St Stanton number of the working fluid;

$\Delta T \quad$ temperature difference, ${ }^{\circ} \mathrm{C}$.

$T_{r} \quad$ design room temperature for space heating, ${ }^{\circ} \mathrm{C}$;

$T_{a m} \quad$ ambient temperature, ${ }^{\circ} \mathrm{C}$;

$T_{\text {f.av }} \quad$ average temperature of the inlet and outlet of the underfloor heating coil, ${ }^{\circ} \mathrm{C}$;

$\Delta T_{m} \quad$ logarithmic mean temperature difference, ${ }^{\circ} \mathrm{C}$;

$T_{t} \quad$ temperature of the water tank, ${ }^{\circ} \mathrm{C}$;

$u \quad$ velocity of the working fluid, $\mathrm{m} / \mathrm{s}$;

$V \quad$ volume flow rate of the working fluid, $\mathrm{m}^{3} / \mathrm{h}$;

$W \quad$ width of the heat exchange tank in novel HSEU, m;

$\alpha \quad$ volume change coefficient of the working fluid;

$\rho \quad$ mass density of the working fluid, $\mathrm{kg} / \mathrm{m}^{3}$;

$\tau \quad$ viscous stress of the working fluid, $\mathrm{N}$;

$\mu \quad$ dynamic viscosity of the working fluid, $\mathrm{Pa} \cdot \mathrm{s}$;

$\lambda$ heat conductivity coefficient of the working fluid or the wall of the heat exchange tube, $\mathrm{W} / \mathrm{m} \cdot{ }^{\circ} \mathrm{C}$;

$\varepsilon \quad$ heat transfer efficiency of the heat exchanger;

$\eta \quad$ solar thermal efficiency of the solar thermal collectors.

\section{Subscripts}

b.c bottom surface of the corrugated tube;

$d \quad$ door of the testing room;

ex.c heat exchange process of the corrugated tube;

fc working fluid in solar thermal collectors;

$f \quad$ working fluid flowing through the underfloor heating coil;

$f c-f \quad$ heat exchange process between the working fluid in solar thermal collectors and the underfloor heating coil;

i.s inner part of the straight tube;

i.c inner part of the corrugated tube;

max maximum temperature difference of the heat exchanger; 


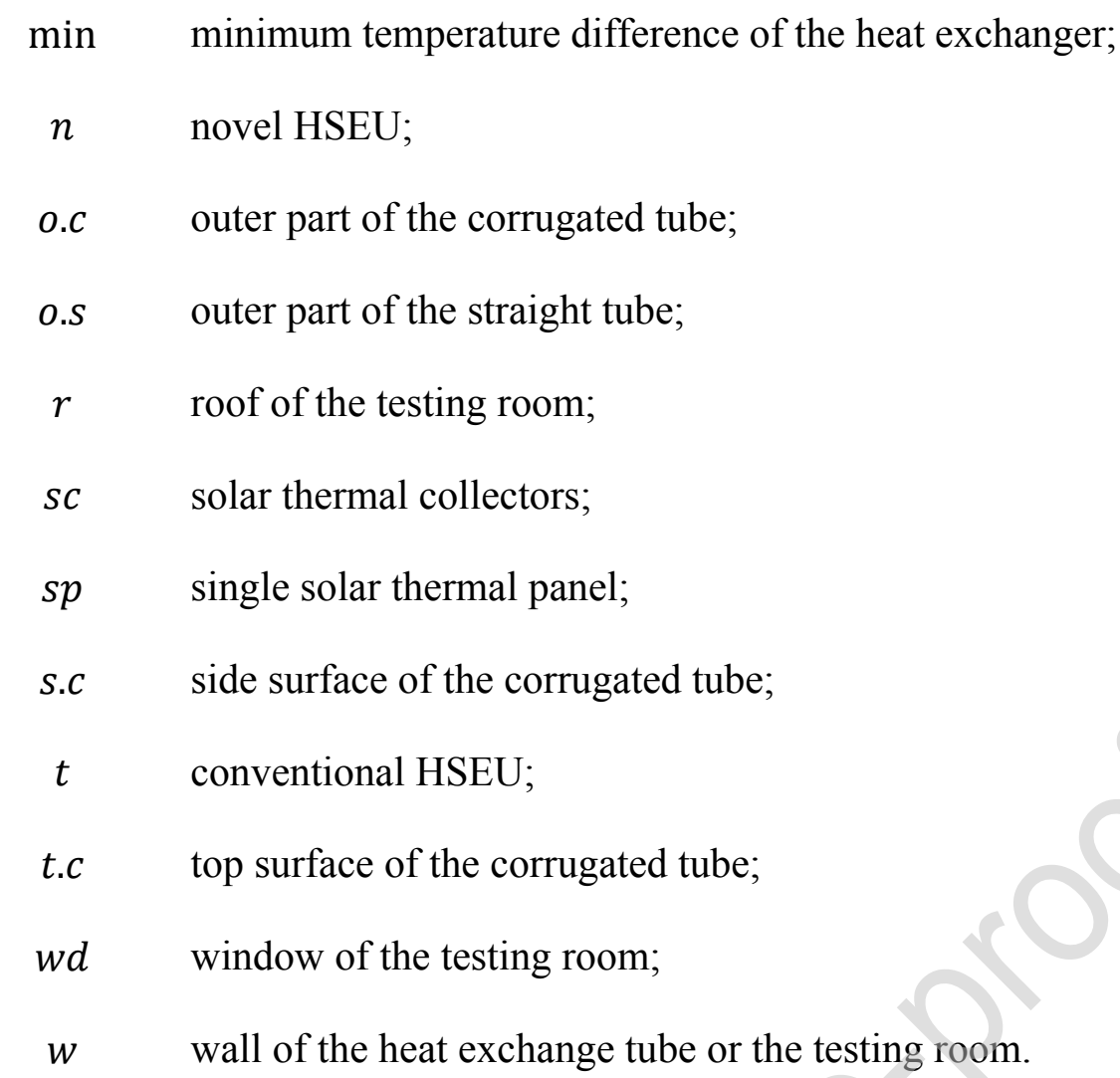

\section{Introduction}

In 2015 the annual building energy consumption in China and the EU was 576 and 225 million tons of oil equivalent respectively (Mtoe) [1, 2], of which 45\% was for space heating, $14 \%$ for hot water supply and $15 \%$ for electricity generation. Solar energy based systems provided just $2.1 \%$ and $10.3 \%$ of the total energy consumed in China and the EU respectively [3]. From this perspective the market potential for developing and implementing energy efficient and costeffective solar heating systems is enormous.

Solar heating systems (SHSs) have been under rapid development over the past few decades. A typical solar heating system (SHS) comprises an integrated solar panel-array, a heat storage/exchanging unit (HSEU), an auxiliary heating device, a primary (solar) loop charged with a solar working fluid and a secondary (heating) loop charged with a heating working fluid. Of these components, the heat storage/exchanging unit (HSEU) plays a critical role in ensuring a stable and secure system operation. The HSEU can store surplus energy, which is created when the solar heat supply is higher than the heat demand of the served space. The stored heat can then be released when the solar radiation is insufficient for providing the required heat for 
the served space. This balanced the gap between the heat supply and demand [4], guaranteed the reliability of the system and secured its energy saving potential [5].

For solar heating systems which employ heat pumps, the HSEUs can significantly enhance their performance regardless of the heat pumps energy source (e.g., air, ground, or water). Kamel conducted a literature review on solar heating systems and their integration with heat pumps, which suggests that thermal storage is preferred to overcome the problem of nonconstant solar radiation intensity [6]. Mohanraj conducted research which showed that energy savings of around 15\% could be achieved in a heat pump-based system using heat storage [7]. Yang investigated the performance of a solar-ground source heat pump system and found that the daytime water tank heat storage mode is particularly suited to buildings with a large shortterm heat load during the night [8]. Zhu combined a seasonal HSEU with a ground air source heat pump, and found that the solar seasonal storage process can significantly improve the COP of a GSHP system [9]. Jradi investigated the performance of a soil-based thermal energy storage system, and stated that the efficient energy storage techniques must be introduced to bridge the energy production-consumption gap and hence eliminate the mismatch between energy generation and demand [10]. Zhao conducted an investigation and feasibility analysis on a capillary radiant heating system based on solar and air source heat pump dual heat source, showing that the solar heating system can significantly raise its energy saving rate by using a heat storage tank [11]. Guo designed a novel heat storage tank which has much better performance than the one in the China national design code and its highest energy saving rate reaches $37.39 \%$ [12]. For an under-floor heating system, the HSEU can lead to a reduction of the heat load of around $40 \%$ for a building of $100 \mathrm{~m}^{2}$ floor area [13]. Furthermore, an HSEU enables an effective reduction of the peak load of the served space, thus leading to a saving on the operational cost of 7.8\% [14]. The combined use of an HSEU and a solar assisted heat pump (SAHP) can lead to up to a 50\% saving in operational costs [15].

Sensible heat storage is the most developed heat storage technology, which makes use of a number of affordable and freely available materials, e.g. water, air, oil, rock beds, bricks, concrete or sand [16]. Water is the best sensible heat storage fluid owing to its abundance and high specific thermal capacity. In particular, the combined use of water-based heat storage and market-available SAHP has become a popular space heating system due to its distinct features of simpler design, installation and control $[17,18]$. 
In a parallel solar heating system the solar panel-array operates in parallel with an air/ground/water source heat pump, thus enabling the heat load of the building to be met by either the solar panel-array or the heat pump. Usually the heat from the solar panel-array and the heat pump are initially stored in a single water tank; this amount of heat is then released to the heating loop fluid to provide space heating and domestic hot water [19-21]. The control logic is that the heat pump operates when the solar collectors cannot meet the heat demand of the served space.

Existing HSEUs are based on a single large-sized water tank which is embedded with heat exchanging coils for heat transfer from the solar panel-array to the bulk of tank water. In general, the heat from the solar panels and heat pump is first stored in the tank, and then released for space heating and domestic hot water generation [22]. The tank, which usually holds a large volume of water in order to store at least one day's heat from the solar panelarray, acts as the heat storage as well as heat provider, thus ensuring the balance between the heat supply from the solar panel-array and heat demand of the served space. Due to the huge volume of water, the time needed for heating up the tank water to the required temperature (i.e. temperature required for the secondary loop fluid to work) is long especially when there is forced heat transfer. This leads to a significant delay in heat delivery to the served space. For example, in the morning when sun rises the heat collected from the solar panel-array cannot be used to provide space heating due to the low tank water temperature. Instead the heat is used to raise the temperature of the tank water until it reaches $40-50^{\circ} \mathrm{C}$. This heating up time could long during which time space heating is unavailable. This would lead to a great thermal discomfort to the occupants, especially when heating is required urgently, hence the heat pump must be brought into use which leads to a significant waste of electricity.

In addition to the above, there are also challenges with respect to the temperature control of a conventional HSEU. First, space heating and domestic hot water supply are basic applications of the SAHP. The temperature requirements for the two applications are different; A temperature of about $35^{\circ} \mathrm{C}$ will be high enough for the underfloor heating system $[23,24]$, while domestic hot water should be stored at $55^{\circ} \mathrm{C}$ or higher in order to kill legionella bacteria $[25,26]$. The SAHP system needs to adjust the temperature when the operating mode changes, which can take place sporadically. With a large single HSEU it is difficult for the system to react quickly to the user's demand. Second, the consumer's demand on heat varies from time to time and the heat load of the building is affected by ambient temperature. Without prompt 
temperature controls the level of comfort will not live up to the residents' expectations.

In order to address the above-mentioned challenges, we developed a novel interactive-doubletanks-based heat storage/exchanging unit (HSEU). It is the first time that a small tank has been incorporated inside a large one in a parallel SAHP application. Unlike the conventional HSEU which has a single tank acting as both the heat storage and exchanging unit, the new HSEU comprises a small tank within a large tank. The small tank is used for the fast transfer of solar heat to the heating loop fluid, without the need to heat up the large bulk of the tank water. The large tank is used for storing and exchanging heat between the small and large tank, directed by a temperature-based control mechanism. Based on this structural and operational innovation, the researchers investigated the heat transfer between the primary (solar loop) and secondary (heating loop) fluids, heat and mass transfer between the small and larger tank, and associated operational strategy by using a combined experimental and theoretical analytic method. The results derived from this research could help to drive the wide deployment of fast responsive and energy efficient solar heating systems in buildings. Hence the novel HSEU could make a significant contribution to reducing fossil fuel energy consumption and carbon emissions on a global scale.

\section{The conceptual development of the novel HSEU against the conventional HSEU}

The schematic of a conventional HSEU is shown in Fig 1. A single water tank is employed as the heat storage and exchanging unit, which is integrated with two coil-type heat exchangers. The first heat exchanger is connected to the solar loop, allowing the working fluid to flow through and transfer heat from the solar loop fluid to the water in the small tank. The working fluid is a glycol based solution with a concentration ratio ranging from $30 \%$ to $40 \%$ and freezing point ranging from $-10^{\circ} \mathrm{C}$ to $-20^{\circ} \mathrm{C}$. The second heat exchanger is connected to the heating loop, allowing the heating loop fluid (i.e., water) to flow through and transfer heat from the tank water to the heating loop fluid. 


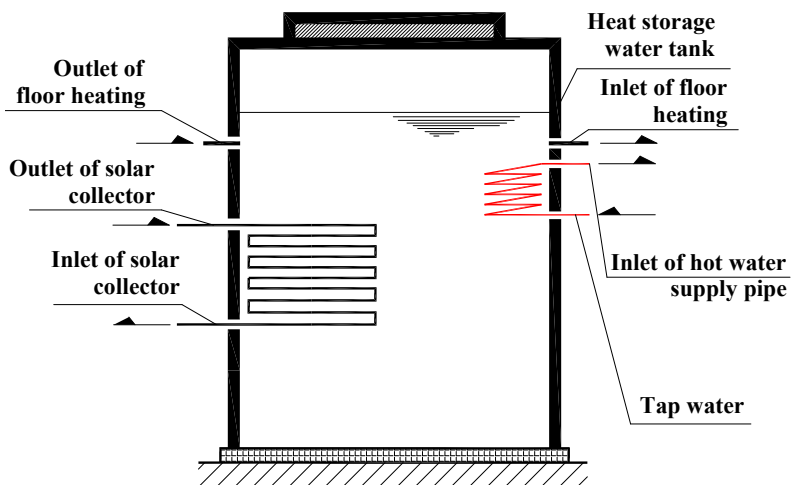

Fig. 1 Schematic of the conventional HSEU employing a single tank configuration

The operational procedure of the conventional HSEU is as follows: (1) When the solar loop fluid temperature is higher than that of the tank water, the fluid is passed through the first coiltype heat exchanger and heat is released to the tank water via the exchanger, leading to a rise of the tank water temperature; (2) When the solar loop fluid temperature is lower than that of the tank water, the solar loop fluid is stopped, leading to no heat transfer between the solar loop fluid and the tank water; (3) When the tank water temperature is higher than that of the heating loop fluid (i.e. water), the fluid is passed through the secondary coil-type heat exchanger and heat is received from the tank water via the exchanger, (4) When the tank water temperature is lower than that of the secondary loop fluid, the valves stop the fluid flow to terminate heat transfer between the tank water and secondary loop fluid. The control scheme of a conventional HSEU is summarized in the flow chart presented in Fig 2.

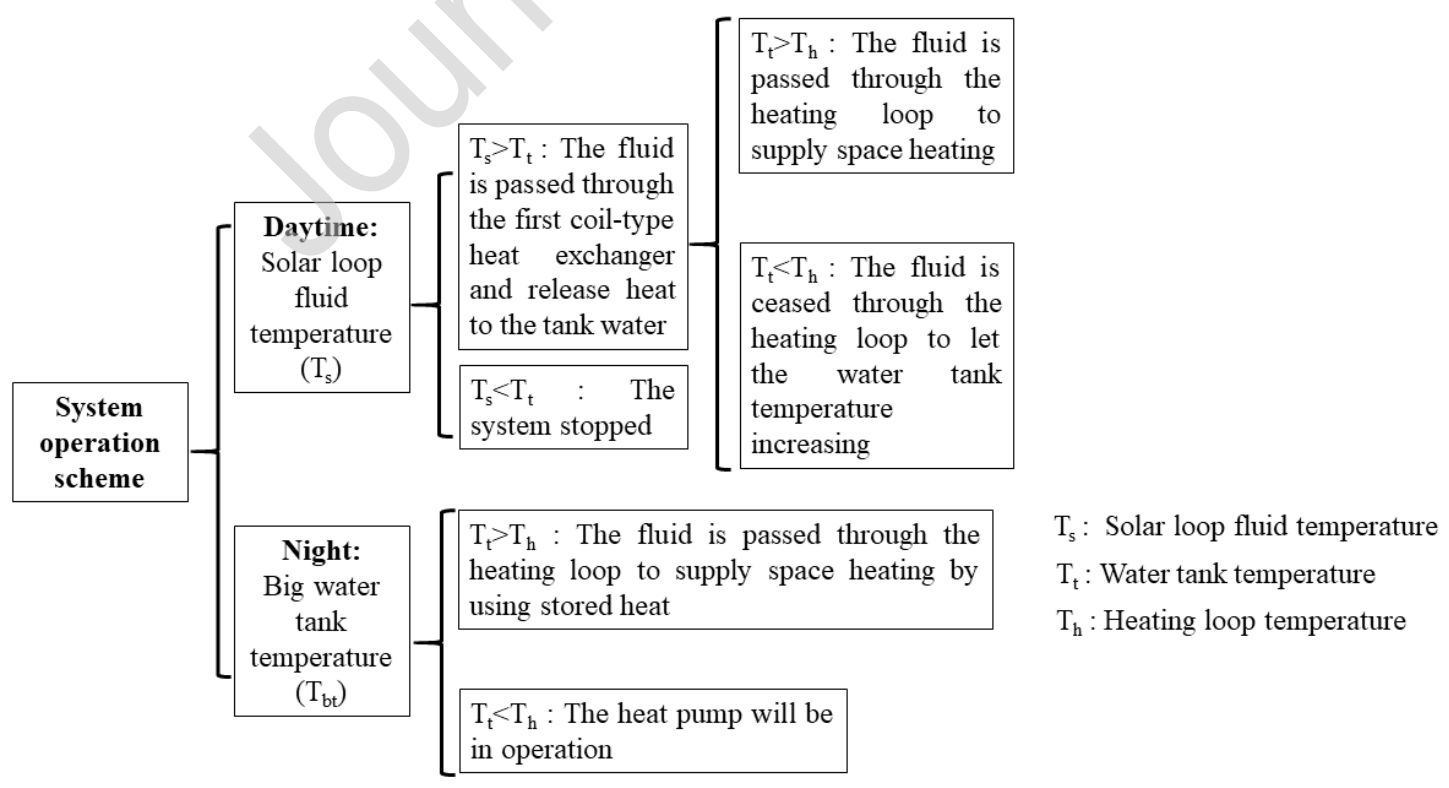

Fig. 2 The control scheme of the operation of the conventional HSEU

The main issue with conventional HSEUs is the very slow response to heat demand which leads 
to significant delays in providing heating to the served space. Due to the large volume of water stored in the HSEU, the heat from the solar panel-array is initially used to heat up the tank water after sunrise. The heating service can only function when the tank water temperature is higher than the required heating loop water temperature for space heating (e.g., $40^{\circ} \mathrm{C}$ ) which normally takes around 3 to 4 hours. As a result, a conventional system is not capable of providing heat during the morning hours (e.g. 8am to 12am) which results in the discomfort to the occupants and acts as a barrier for wider applications in buildings. To accelerate the heating provision a heat pump is usually brought into use, which uses electrical energy, creates some energy waste and hence leads to poor energy efficiency for the system.

To overcome this issue, the authors of this paper have developed a novel interactive-doubletanks-based heat storage/exchanging unit (HSEU) which is shown schematically in Fig. 3. Unlike the conventional HSEU which has a single tank acting as both the heat storage and exchanging unit, the new HSEU comprises a small tank within a large tank. The small tank is used for the fast transfer of solar heat to the heating loop fluid, without the need to heat up the large bulk of the tank water. The large tank is used for storing and exchanging heat between the small and large tank, directed by a temperature-based control mechanism. The water in the small tank is directly conveyed to the heating loop as part of the loop water.

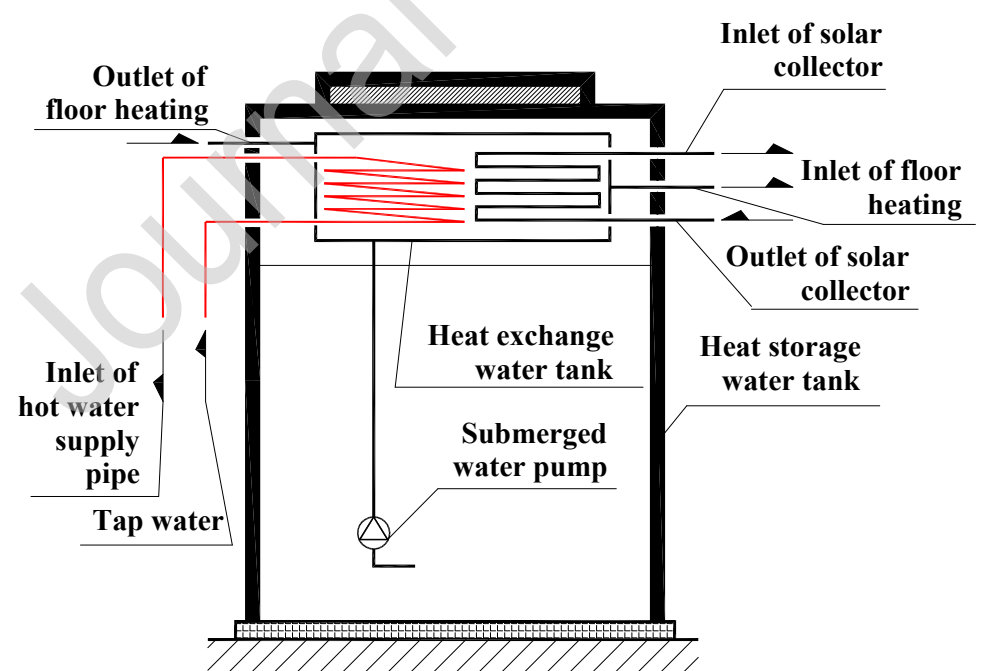

Fig.3 Schematic of the novel HSEU employing double tanks

The control scheme of the proposed novel HSEU is divided into three main steps: (1) When the solar loop fluid temperature is higher than that of the heating loop fluid, the pump on the solar loop will operate to transfer the collected heat from the solar panel-array to the secondary heating loop fluid; (2) When the heat accumulated by the collectors is higher than the heat 
demand of house, the heat storage process operates by using the submerged pump; (3) When the solar loop fluid temperature is less than that of the heating loop fluid, and the room temperature reaches the lower limit, the heat release process takes place by using the stored heat to provide space heating. The operational control scheme of the new HSEU is shown in Fig. 4.

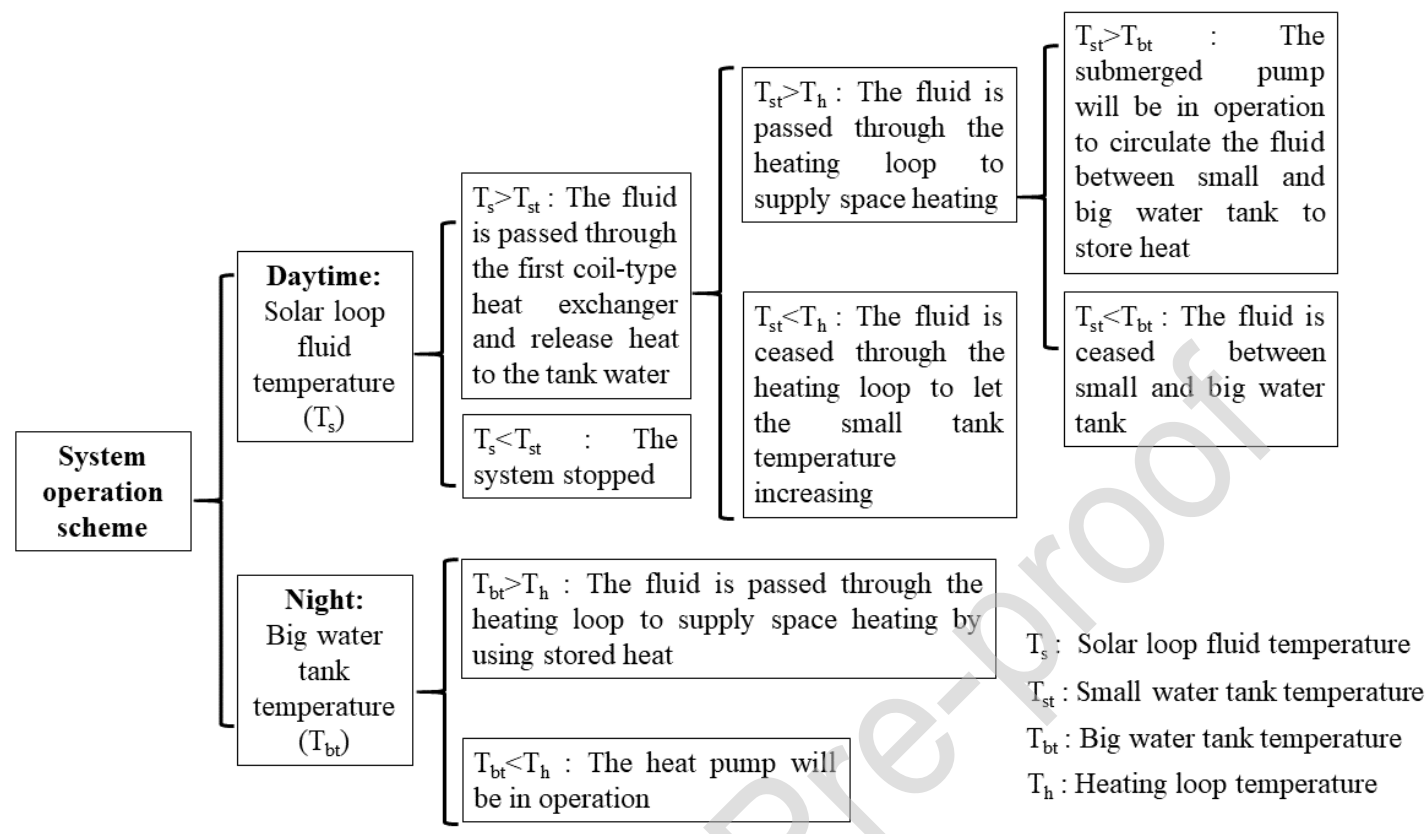

Fig. 4 The control scheme of the novel HSEU operation

\section{Mathematical equations and computer model set-up}

\subsection{Heat transfer process in the HSEUs}

\subsubsection{The heat exchange areas of corrugated and normal tubes}

The corrugated tubes, as shown in Fig. 5, are used as the basic heat transfer elements of the heat exchanger. The advantages of the corrugated tubes are: (1) increased heat transfer area; (2) decreased length of tube with the same heat exchanging area, and (3) high convective heat transfer coefficient. 


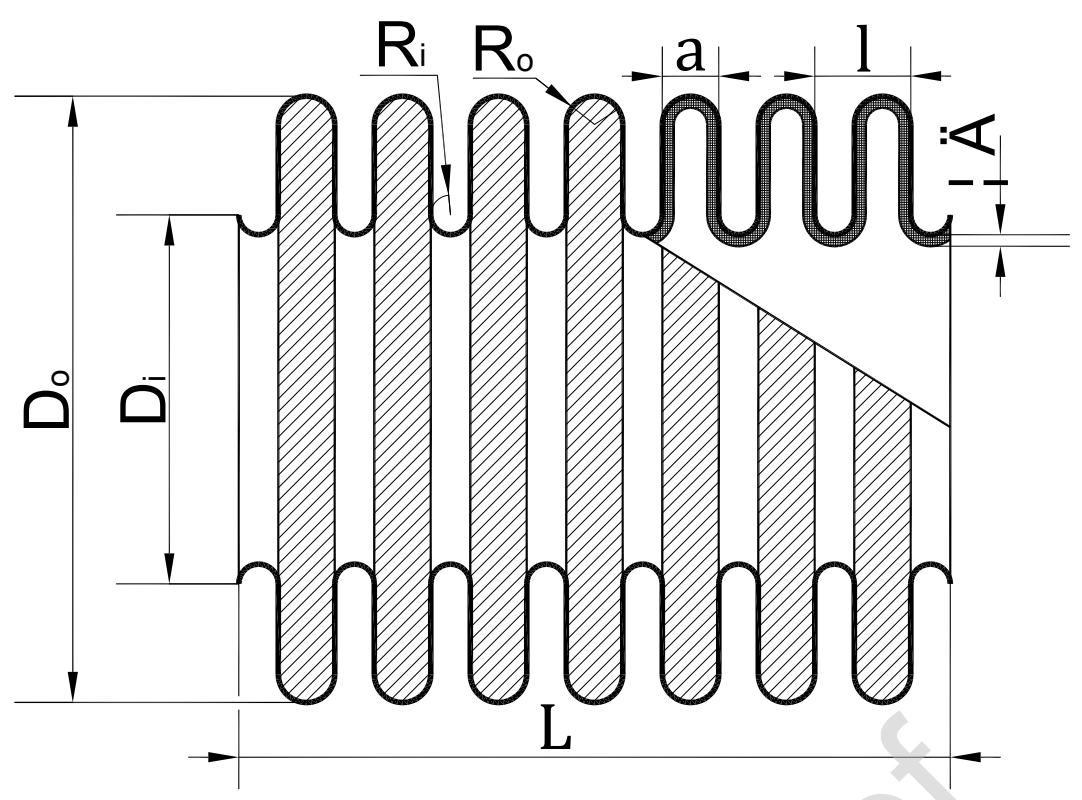

Fig. 5. The configuration of the corrugated heat exchange tube

The heat exchange area of the corrugated tube can be expressed as:

$$
S_{\text {ex.c }}=S_{s . c}+S_{b . c}+S_{t . c}
$$

Where $S_{s . c}, S_{b . c}$ and $S_{t . c}$ can be expressed as:

$$
\begin{gathered}
S_{S . c}=2 N \pi \frac{D_{o . c}^{2}-D_{i . c}^{2}}{4} \\
S_{b . c}=N \pi^{2} D_{o . c} R_{o . c} \\
S_{t . c}=N \pi^{2} D_{i . c} R_{i . c}
\end{gathered}
$$

The numerical values for $D_{o . c}, R_{o . c}, D_{i . c}$ and $R_{i . c}$ in Eqs. 2 and 4, are given in Table 1.

Table 1. List of parameters shown in Equations 2-4

\begin{tabular}{|c|c|c|c|}
\hline Name & Value & Name & Value \\
\hline$D_{\text {o.c }}$ & $0.015 \mathrm{~m}$ & $R_{\text {o.c }}$ & $0.0015 \mathrm{~m}$ \\
\hline$D_{i . c}$ & $0.012 \mathrm{~m}$ & $R_{i . c}$ & $0.0015 \mathrm{~m}$ \\
\hline
\end{tabular}

$N$ is the number of folds along per meter corrugated tube $(/ \mathrm{m})$, and can be represented as:

$$
N=1 / l
$$

In Eq.5, $l$ is the length of the fold along the corrugated tube, taken as $0.006 \mathrm{~m}$ in these two systems.

According to Eq.5, the number of folds along per meter length of corrugated tube is 167 . As a 
result, the heat exchange area per meter length corrugated tube is $0.087 \mathrm{~m}^{2}$. Furthermore, a normal straight tube is used for constructing the heat exchange coil.

The heat exchange area per meter length of normal straight tube can be expressed as:

$$
S_{e x, s}=\pi \frac{D_{0 . s}+D_{i . s}}{2}
$$

The heat exchange area per meter length of normal straight tube is calculated as $0.041 \mathrm{~m}^{2}$ from $\mathrm{Eq}, 6$. Hence, the heat exchange area per meter length of a corrugated tube is more than twice that of a normal straight tube. This means that for the same length of heat exchange tube, the corrugated tube has more heat exchange area. Furthermore, if the same heat exchange area of two kinds of heat exchange tube was needed, then the corrugated tube will have a shorter length and thus it can save more space.

\subsubsection{Convective heat transfer coefficient of the working fluid within the heat exchange tube}

The convective heat transfer coefficient of the working fluid is a key factor in the heat transfer process of the heat exchanger. Due to the corrugated configuration, the corrugated tubes can create a higher convective heat transfer coefficient under the same conditions as the normal straight tubes. The calculation of the convective heat transfer coefficient for the working fluid within the corrugated tube is given as:

Stanton number of the heat transfer process in the working fluid can be expressed as [27]:

$$
S t_{f c}=\frac{h_{f c}}{\rho_{f c} C_{p f c} u_{f c}}=\frac{\tau_{f c}}{\rho_{f c} u_{f c}{ }^{2}}
$$

According to Eq.7, convective heat transfer coefficient of the heat transfer process in the corrugated tube can be derived as:

$$
h_{f c}=\frac{\tau_{f c} C_{p f c}}{u_{f c}}
$$

The pressure drop, $\Delta p$, along the tube is caused by the viscous stress, $\tau_{f c}$. As a result, the balance between the pressure drop and the viscous stress can be expressed as [28]:

$$
\tau_{f c} L \pi D_{i, c}=\Delta p_{4}^{\pi} D_{i, c}^{2}
$$

Then the viscous stress $\tau_{c}$ is derived as: 


$$
\tau_{f c}=\frac{\Delta p D_{i, c}}{4 \quad L}
$$

The pressure drop $\Delta p$ along the corrugated tube can be expressed as [29]:

$$
\Delta p=f \frac{L \rho_{f c} u_{f c}^{2}}{D_{i, c} \quad 2}
$$

Combining Eq. 10 with Eq. 11, viscous stress $\tau_{f c}$ equation can be re-written as:

$$
\tau_{f c}=\frac{f}{8} \rho_{f c} u_{f c}^{2}
$$

The frictional resistance coefficient of the corrugated tube can be expressed as [30]:

$$
f=\left[2 * \lg \left(\frac{R_{i . c}}{k_{s}}\right)+1.74\right]^{-2}
$$

By using Eqs. 7 to 13, the convective heat transfer coefficient of the working fluid of the corrugated tube was calculated as $11,540 \mathrm{~W} /\left(\mathrm{m}^{2} \cdot \mathrm{K}\right)$.

\subsubsection{The convective heat transfer coefficient of the working fluid in the novel HSEU small water tank}

The Reynold number of the flowing process in the working fluid in the heat exchange water tank can be expressed as:

$$
\operatorname{Re}_{f . n}=\frac{\rho_{f} u_{f} D_{o . c}}{\mu_{f}}
$$

Where, the velocity of the working fluid can be expressed as:

$$
u_{f . n}=V_{f} / 3600(W a)
$$

The structural layout of the heat exchanger in the small tank of the novel HSEU is shown in Fig.6. 


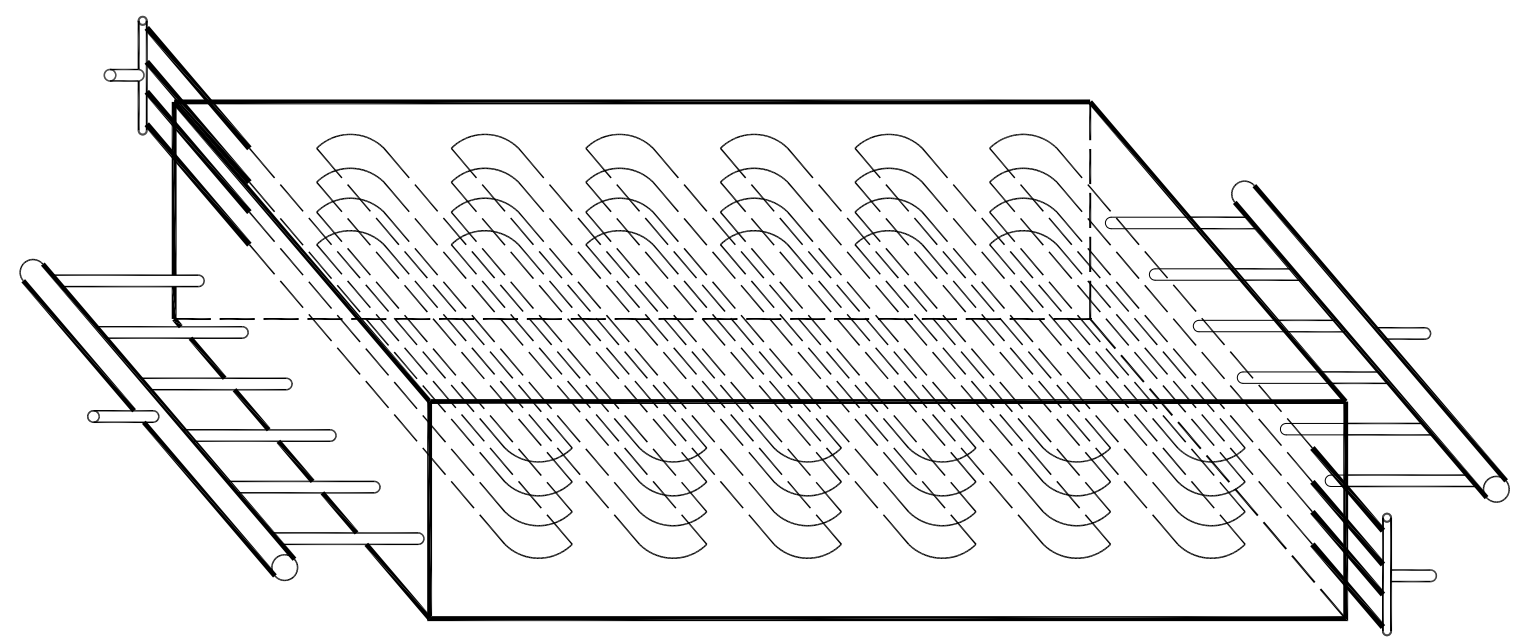

Fig. 6. The construction of $60 \mathrm{~L}$ heat exchange water tank

The average velocity and the Reynold number of the working fluid inside the heat exchange tank are around $0.01 \mathrm{~m} / \mathrm{s}$ and 200 respectively. The Nusselt number of the heat exchange process in the working fluid within the heat exchange tank can be expressed as [31]:

$$
N u_{f . n}=C \operatorname{Re}_{f . n}^{n} \operatorname{Pr}_{f . n}^{0.37}\left(\frac{P r_{f . n}}{P r_{w . n}}\right)^{0.25}
$$

Where the constant numbers $C$ and $\mathrm{n}$ are listed in Table 2 .

Table 2. List of parametrical data for Eq.16

\begin{tabular}{|c|c|c|}
\hline$R e$ & $\mathrm{C}$ & $\mathrm{n}$ \\
\hline $1 \sim 40$ & 0.75 & 0.4 \\
\hline $40 \sim 1 \times 10^{3}$ & 0.51 & 0.5 \\
\hline $1 \times 10^{3} \sim 2 \times 10^{5}$ & 0.26 & 0.6 \\
\hline
\end{tabular}

Hence, the convective heat transfer coefficient of the heat exchange process in the working fluid within the heat exchanging water tank can be expressed as:

$$
h_{f . n}=N u_{f . n} \frac{\lambda_{f}}{D_{o . c}}
$$

Following the procedure described above, the convective heat transfer coefficient of the working fluid within the heat exchanging water tank was calculated as $391 \mathrm{~W} /\left(\mathrm{m}^{2} \cdot \mathrm{K}\right)$. 


\subsubsection{Convective heat transfer coefficient of the working fluid within the conventional water tank}

In a conventional water storage tank, natural convection is the major flow state of the fluid around the corrugated heat exchange tube. The heat exchange process between the wall of the corrugated heat exchange tube and the water can be approximated to a vertical flat wall natural convection heat exchange process, which is shown schematically in Fig.7.

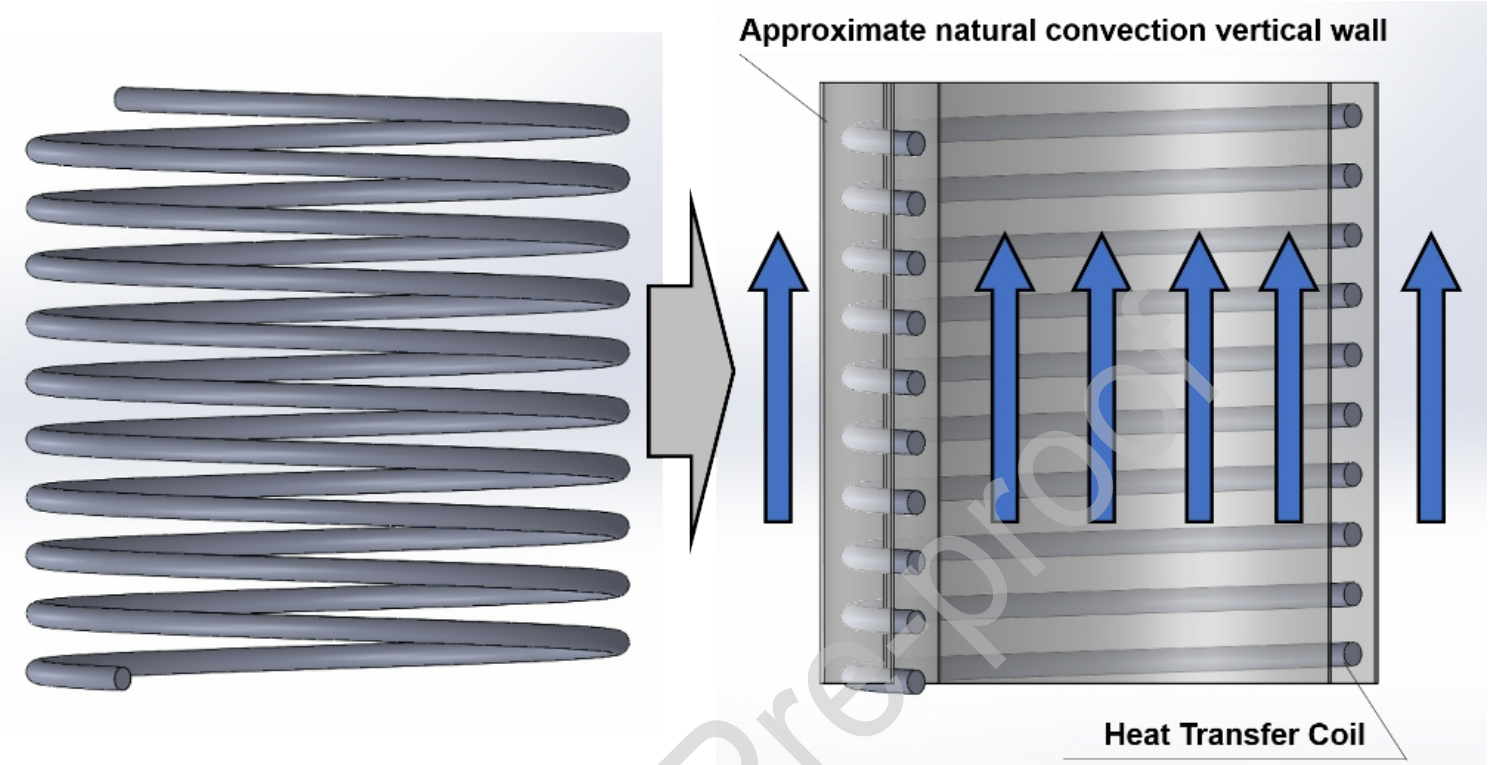

Fig. 7. The approximate natural convection process

The Nusselt number of the heat exchange process in the working fluid can then be expressed as:

$$
\begin{gathered}
N u_{f . t}=0.59\left(G r_{f . t} \cdot P r_{f . t}\right)^{1 / 4} \\
G r_{f . t}=\frac{g \alpha_{f} \Delta T l^{3}}{v_{f . t}{ }^{2}} \\
h_{f . t}=N u_{f . t} \frac{\lambda_{f}}{l}
\end{gathered}
$$

Hence, the heat transfer coefficient can be expressed as:

$$
k_{f c-f}=\frac{1}{\frac{1}{h_{f}}+\frac{\delta}{\lambda_{w}}+\frac{1}{h_{f c}}}
$$

\subsection{Heat transfer efficiency}

The exchanged heat in the new and conventional HSEUs can be expressed as:

$$
Q_{e x}=S_{e x . c} k_{f c-f . c} \Delta T_{m}
$$


The $\mathrm{Q}_{\mathrm{ex}}$ can also be expressed as:

$$
Q_{e x}=c_{p f c} m_{f c}\left(T_{f c . i n}-T_{f c . o u t}\right)
$$

The logarithmic mean temperature difference $\Delta T_{m}$ can be expressed as:

$$
\begin{gathered}
\Delta T_{m . n}=\frac{\Delta T_{\max }-\Delta T_{\min }}{\ln \frac{\Delta T_{\max }}{\Delta T_{\min }}} \\
\Delta T_{m . t}=\frac{T_{f c . i n}-T_{f c . o u t}}{\ln _{\text {fc.in }}-T_{t}}
\end{gathered}
$$

The theoretical heat exchange efficiency [32] of the new and conventional HSEUs can be expressed as:

$$
\begin{aligned}
\varepsilon & =\frac{A k \Delta T_{m}}{m c\left(T_{f . i n}-T_{f c . i n}\right)} \\
\varepsilon & =\frac{A k \Delta T_{m}}{m c\left(T_{f c . i n}-T_{t}\right)}
\end{aligned}
$$

The experimental heat exchange efficiency of the new and conventional HSEUs can be expressed as:

$$
\begin{aligned}
\varepsilon & =\frac{T_{f . \text { in }}-T_{f . \text { out }}}{T_{f . \text {.in }}-T_{f c . i n}} \\
\varepsilon & =\frac{T_{f c . i n}-T_{f c . o u t}}{T_{f c . i n}-T_{t}}
\end{aligned}
$$

The equations 22-29 were all incorporated in the computer model and the model outputs are presented in following sections.

\subsection{Computer model set-up and operational flow diagram}

A detailed computer model was developed to simulate the temperature variation process and the heat exchange efficiency of the new and conventional HSEUs. The simulation results are compared with the experimental data to validate the accuracy and effectiveness of the computer model. The experimental data was the average value of the measurement parameter in every 5 minutes. The flow chart diagram of the developed model is shown in Fig.8. 


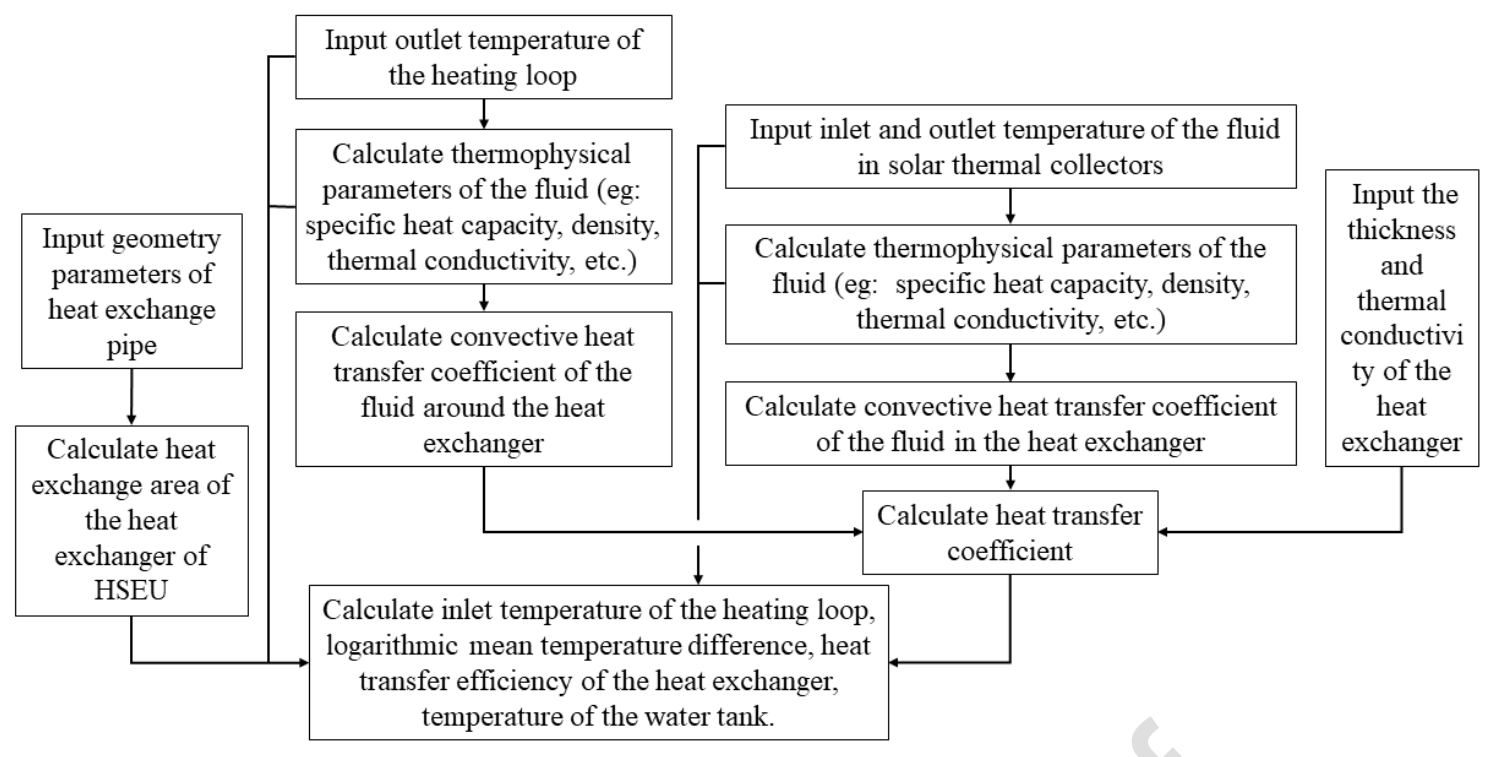

Fig.8. The flow chart of the computer model

\section{Experimental system and testing procedure}

\subsection{System description}

Two identical experimental systems were established, one equipped with a conventional HSEU and the other with our novel HSEU. The system consists of 16 solar panels (which form an integrated solar panel-array), an HSEU and a heat pump. This system enables: (1) collection and conversion of the solar radiation from the solar panel-array into useful heat; (2) transfer of the solar heat to either the HSEU tank water or heating loop fluid and (3) transfer and transportation of the solar/tank heat into the served space via the HSEU and the heating elements fitted into the served space.

The conventional HSEU has a 1500L water tank incorporating a coil-type-heat-exchanger connected to the solar collectors loop and another coil-type-heat-exchanger connected to the heating loop. The in-lab configuration display of the conventional HSEU is shown in Fig. 9.

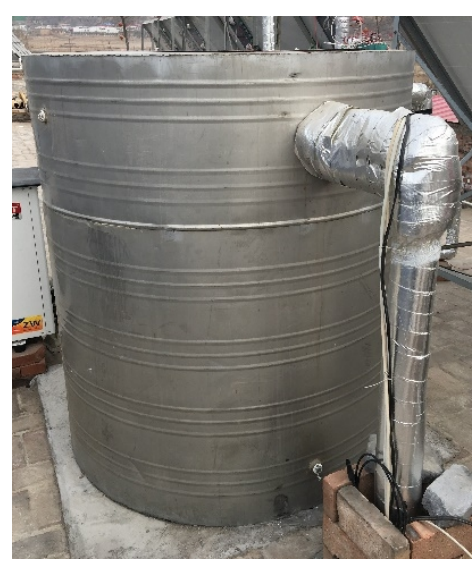

Fig. 9 Configuration display of the conventional HSEU as created in the laboratory 


\section{environment}

The new HSEU comprises: (1) a 1500L large heat storage tank to store heat in the tank water when the solar irradiation is high and discharge heat to the room space when the solar irradiation is low; (2) a 60L small water tank fixed into the HSEU which connects to the heating loop and contains a coil-type-heat-exchanger connected to the solar array. The coil-type-heatexchanger is made of a number of $40 \mathrm{~m}$ long special stainless-steel corrugated pipes which were divided into 4 parallel rows, and were attached to the small water tank; (3) a submerged water pump. The configuration display of the novel double-tank HSEU is shown in Fig. 10, and its technical data are listed in Table 3.

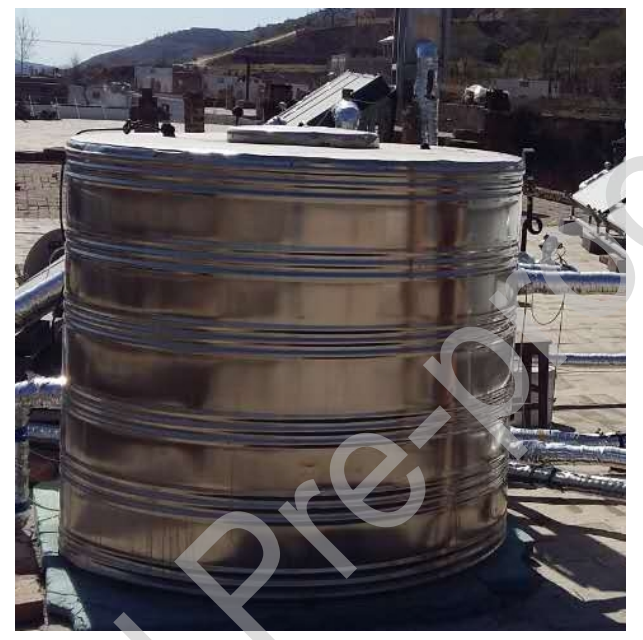

Fig. 10. Configuration display of the novel double-tank HSEU

Table 3 The technical data of the heat exchange and storage water tank

\begin{tabular}{lcll}
\hline & \multicolumn{3}{c}{ Storage tank value } \\
\hline Height & $1380 \mathrm{~mm}$ & Area & $0.66 \mathrm{~m}^{2}$ \\
\hline Diameter & $1190 \mathrm{~mm}$ & Volume & $1.5 \mathrm{~m}^{3}$ \\
\hline Thickness of insulation & $50 \mathrm{~mm}$ & & \\
\hline
\end{tabular}

Two identical test rooms were used to operate and test the systems. The test rooms have a length of $14 \mathrm{~m}$, width of $7 \mathrm{~m}$ and height of $4 \mathrm{~m}$ and a floor area of $100 \mathrm{~m}^{2}$. The front façade of the house faces south. The heat transfer coefficients of building envelopes are listed in Table 4, which are measured using a BES-GP intelligent multi-channel temperature/heat flow detector. Thermal properties of the building components are the same as the actual parameters of common rural houses, thus enabling a real reflection of the heat load for a rural house. 
Table 4. The heat transfer coefficients of the building envelope

\begin{tabular}{ccc}
\hline Part & Structure & $\mathrm{K}$ \\
Wall & $370 \mathrm{~mm}$ brick wall Plastering $+50 \mathrm{~mm}$ extruded polystyrene \\
board & {$\left[\mathrm{W} /\left(\mathrm{m} 2 \cdot{ }^{\circ} \mathrm{C}\right)\right]$} \\
External & Pinewood door & 0.47 \\
doors & $3 \mathrm{~mm}$ common glass aluminum alloy window frame (two & 2.9 \\
Window & layers) & 1.54 \\
Roof & Cement mortar + Insulation layer + Waterproof layer + Tile. & 0.37 \\
\hline
\end{tabular}

\subsection{The testing process and instruments}

The two experimental systems, one with the conventional HSEU and the other with the new HSEU, were equipped with various measurement instruments and sensors. The temperature, flow rate and pressure of the fluids in the solar and heating loops were measured using platinum resistance thermometer probes, flow meters and pressure gauges respectively. All the outputs of the sensors and instruments were transmitted into a Data Logger and then stored on the computer. The specifications, quantity and installation position of the sensors/meters used in the measurement process are outlined in Table 5. The tests were carried out under real-time operational conditions in Lvliang city, China, which has a typical dry climatic condition and enjoyed the sun shining on most days of the year.

Table 5. List of experimental testing and monitoring devices

\begin{tabular}{|c|c|c|c|}
\hline Devices & Specifications & Quantity & Location \\
\hline Pyranometer & TQB-2C (Sunlight, China) & 1 & Top of the collector \\
\hline $\begin{array}{l}\text { Water } \\
\text { flowmeter }\end{array}$ & $\begin{array}{l}\text { LWGY-MK- } \\
\text { DN25(MACON China) }\end{array}$ & 2 & $\begin{array}{l}\text { One branch of solar thermal } \\
\text { panels; solar thermal panels } \\
\text { main entrance; }\end{array}$ \\
\hline Anemometer & $\begin{array}{l}\text { HS-FS01(Huakong single, } \\
\text { China) }\end{array}$ & 1 & Top of the collector \\
\hline $\begin{array}{l}\text { Platinum } \\
\text { resistance }\end{array}$ & PT1000(Zhongjia China) & 40 & $\begin{array}{l}\text { solar thermal panels; testing } \\
\text { room; water tank; ambient, etc. }\end{array}$ \\
\hline
\end{tabular}




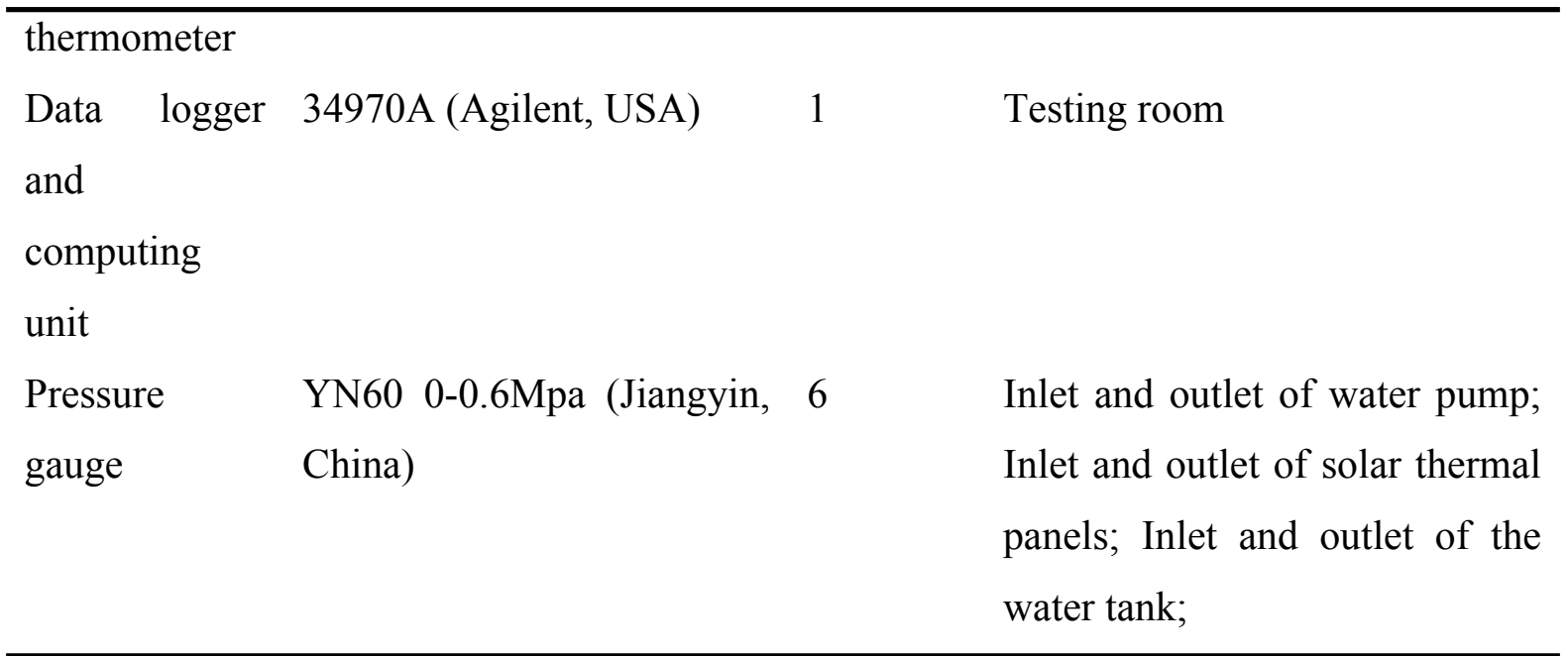

In order to take into account the temperature stratification of the water tank, 5 platinum resistance thermometers (TM_1 to TM_5) were installed at various depths as shown in Fig. 11. The average temperature of the water tank can be calculated by taking an average of the collected data from the thermometers.

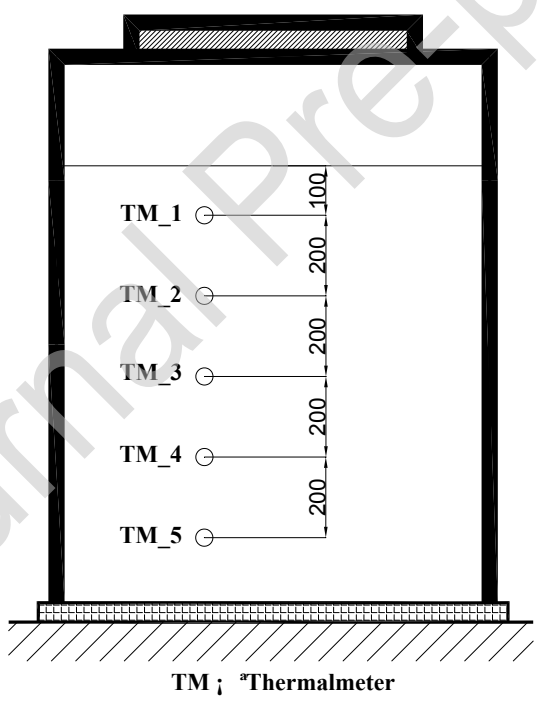

Fig.11 The distribution of the thermometers in the water tank

\section{Results and discussion}

The simulations were run using the exact same conditions as the experiments in order to enable comparison of key performance parameters of the system. Such comparison allows the calibration of computer models and provides solid grounds for drawing conclusions from the system performance. The simulation and experimental results were also compared to each other in order to investigate the operational performance of the new HSEU against the conventional one. The following sections provide details of the 
calibration and comparison work carried out.

To assess the performance of the HSEUs, a comparison of theoretical and experimental results of the two systems, with new and conventional HSEUs, was undertaken. To enhance the reliability of the assessment, three representative days in December 2017 namely, $22^{\text {nd }}, 23^{\text {rd }}$, and $24^{\text {th }}$, were chosen to perform this analysis.

Fig. 12 and Fig. 13 show the variation of the ambient temperature and the solar radiation at $22^{\text {nd }}, 23^{\text {rd }}$, and $24^{\text {th }}$ respectively. According to the figures, the ambient temperature and the solar radiation increased gradually from around 9:30 to 13:30, and decreased from around 13:30 to $16: 30$ during the three days. However, due to unstable atmospheric flow and intermittent cloud cover, the ambient temperature and the solar radiation experienced unexpected fluctuations, and thus the performances of the HSEUs were influenced by the weather conditions.

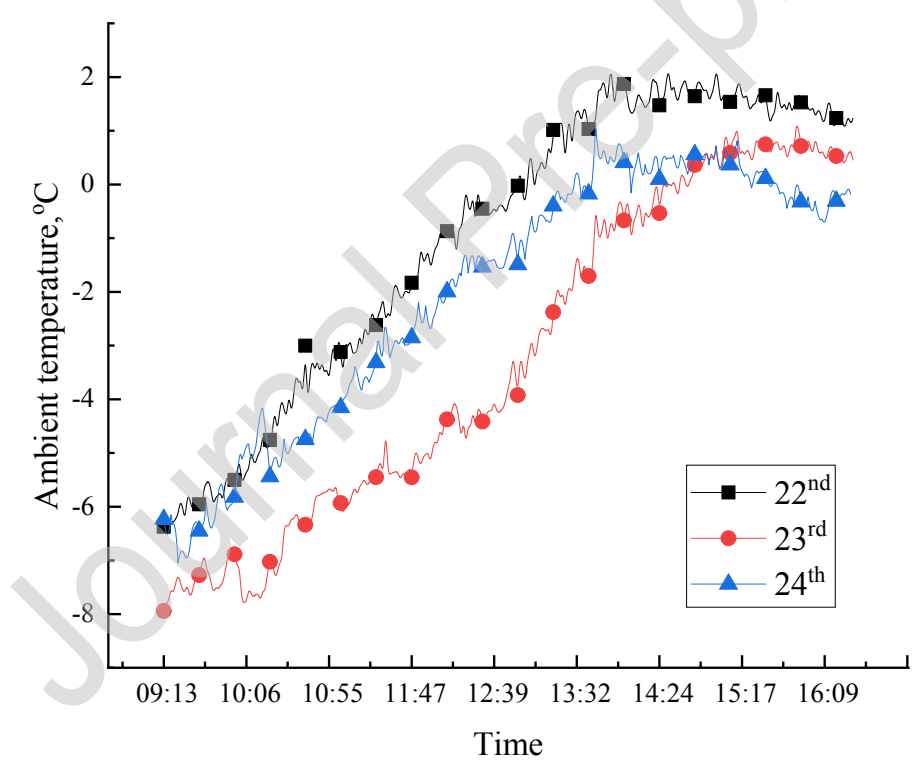

Fig. 12. Variation of the ambient temperature at $22^{\text {nd }}, 23^{\text {rd }}$ and $24^{\text {th }}$ 


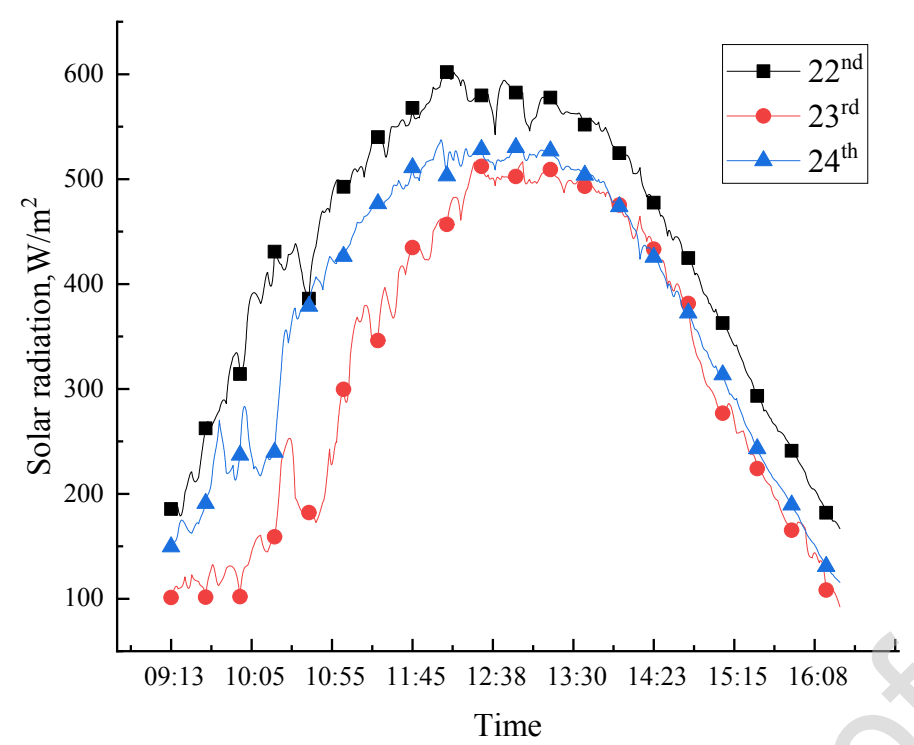

Fig. 13. Variation of solar radiation at $22^{\text {nd }}, 23^{\text {rd }}$ and $24^{\text {th }}$

\subsection{Start-up time of the systems with the new and conventional HSEUs}

Figures14-16 present theoretical and experimental average temperature variations of the water tanks for each system. As seen in the figures, experimental and simulation results are in close agreement, with just small deviations ranging from $0.1 \%$ to $5 \%$. Since the simulation did not take into account the heat loss and thermal inertia of the HSEU, this means that the experimental temperature of the HSEUs is slightly lower than that of the simulation data. Additionally, Figs. 14, 15 and 16 present a rapid water temperature escalation in the new HSEU, giving a 35 minute time span for the temperature rise while the conventional HSEU has a time span of 175 minutes for a similar temperature rise. This shows that the new HSEU has a much faster temperature response compared to the traditional HSEU, which significantly reduces the period that heating is unavailable. Such a fast response will mitigate the possible thermal discomfort of occupants and increase the marketability of heat pump system. 


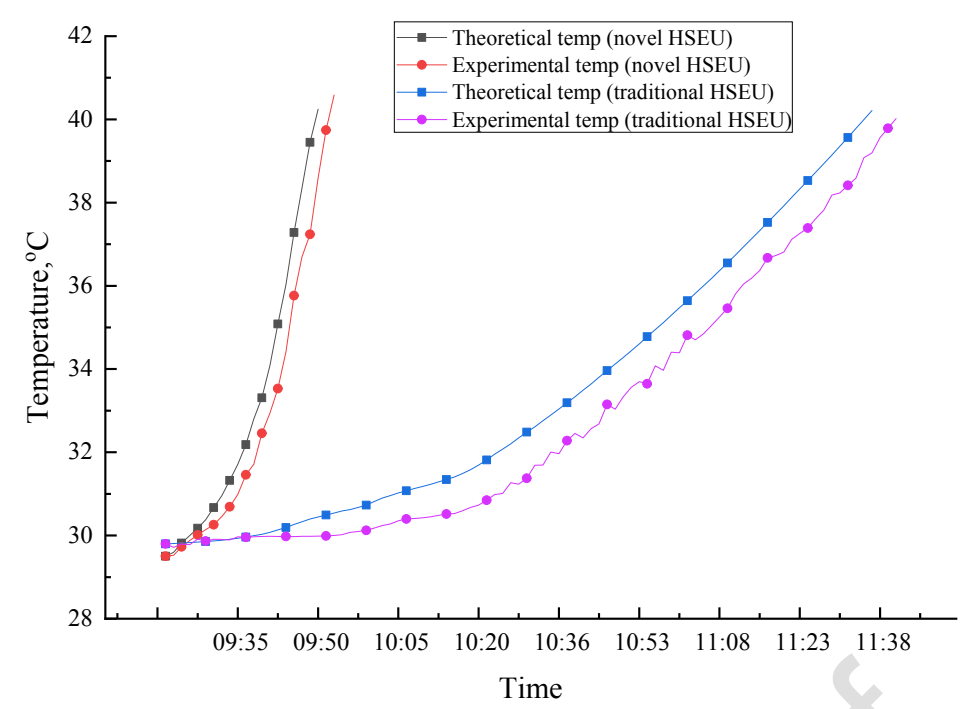

Fig. 14. Variation of the water temperature in the HSEUs $22^{\text {nd }}$ Dec

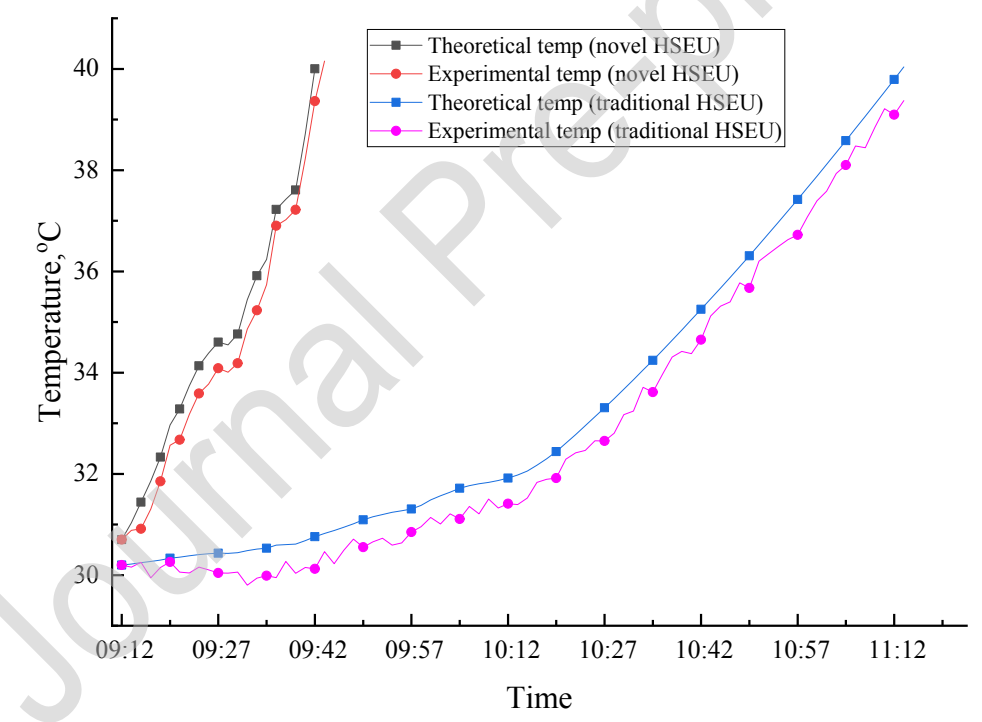

Fig. 15. The variation of temperature of the HSEUs $23^{\text {rd }}$ Dec 


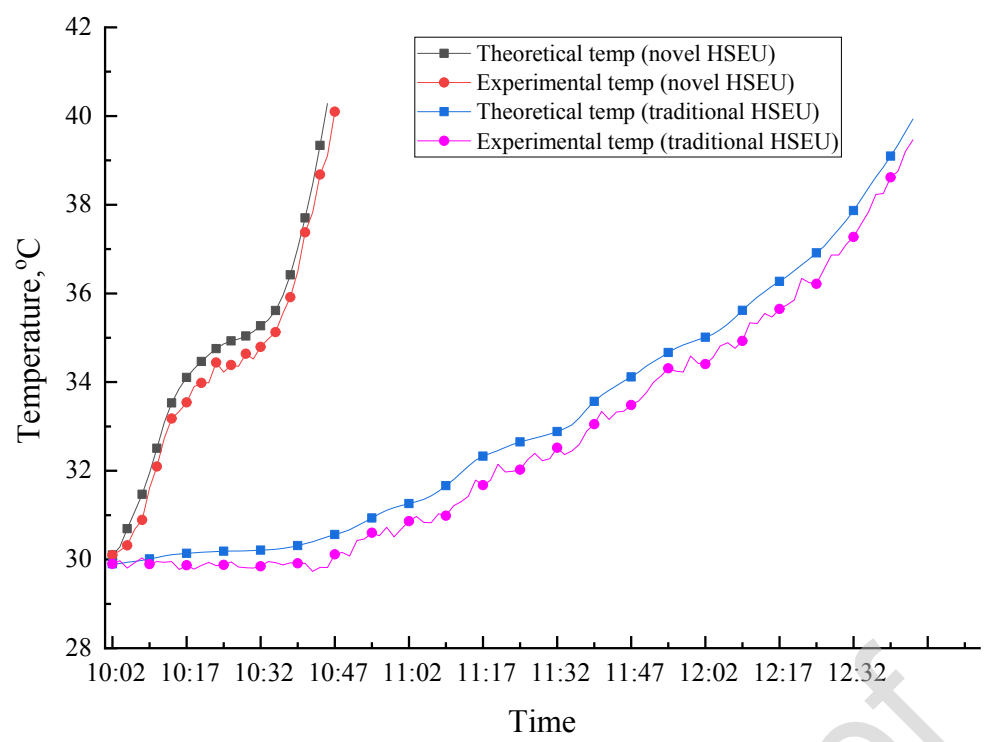

Fig. 16. The variation of temperature of the HSEUs $24^{\text {th }}$ Dec

\subsection{Impact of the HSEUs on the served space temperature}

The configuration of the HSEUs directly influence the variation of the temperature in the served space. Fig. 17 shows the testing room temperature data recorded from 9:00 to 12:00 on $24^{\text {th }}$ December 2017. Compared to the room with the conventional HSEU, which has a warmup time of 240 minutes and a temperature rise from $16^{\circ} \mathrm{C}$ to $19^{\circ} \mathrm{C}$, the room with the new HSEU has a shorter warm-up time of 120 minutes for the air temperature to rise to the same level. The faster rise of room temperature can effectively reduce the thermal discomfort to the occupants and thus increase the commercial attractiveness of the solar heating systems.

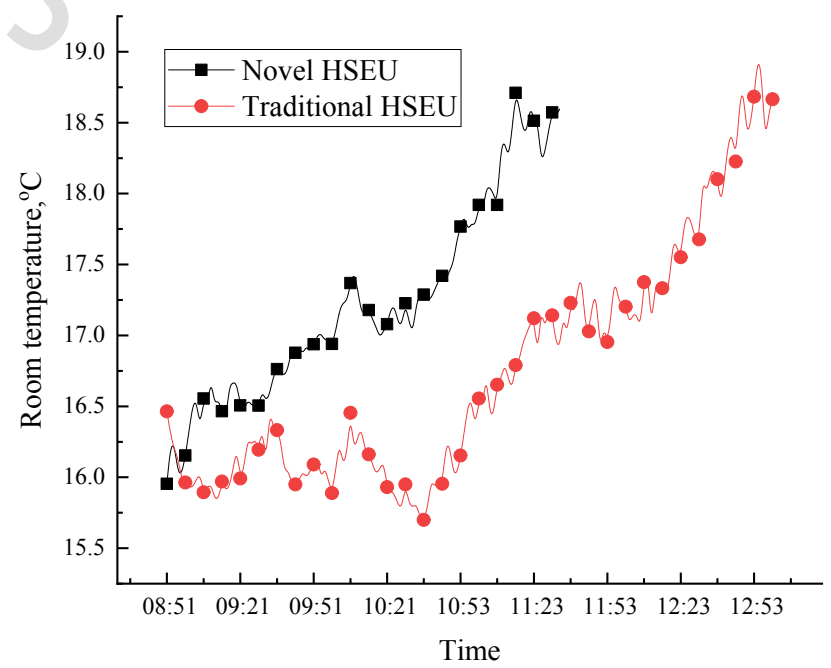


Fig.17 The variation of room temperature for the two HSEUs

\subsection{Comparison of the heat exchange efficiency of the HSEUs}

Fig.18 shows the variation of the heat exchange efficiency against $\Delta T_{m} / \Delta T_{\max }$ for the new HSEU. Comparing the modeling and experimental heat transfer efficiencies, it was found that both the experimental and modeling data agreed closely, giving deviations of $0.1 \%$ to $10 \%$.

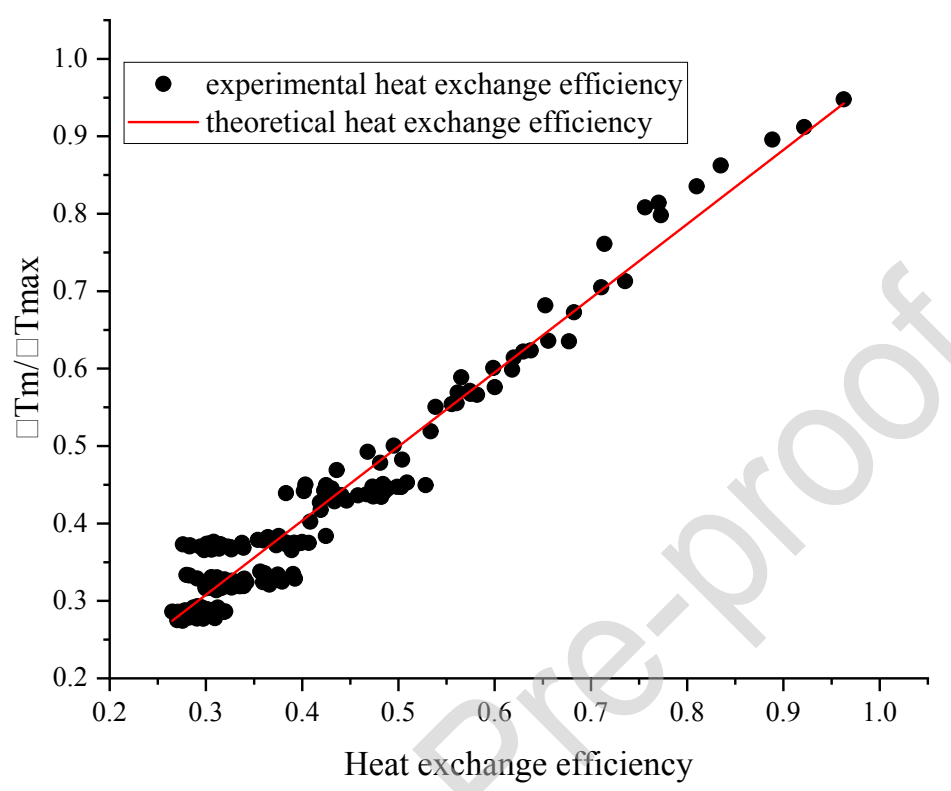

Fig. 18 The heat transfer efficiency of the novel HSEU

Fig.19 shows the variation of the heat exchange efficiency against $\Delta T_{m} / \Delta T_{\max }$ for the conventional HSEU. Comparing the modeling and experimental heat transfer efficiencies, the deviations were found to range from $0.1 \%$ to $10 \%$, indicating a good agreement between the experimental and modeling data. 


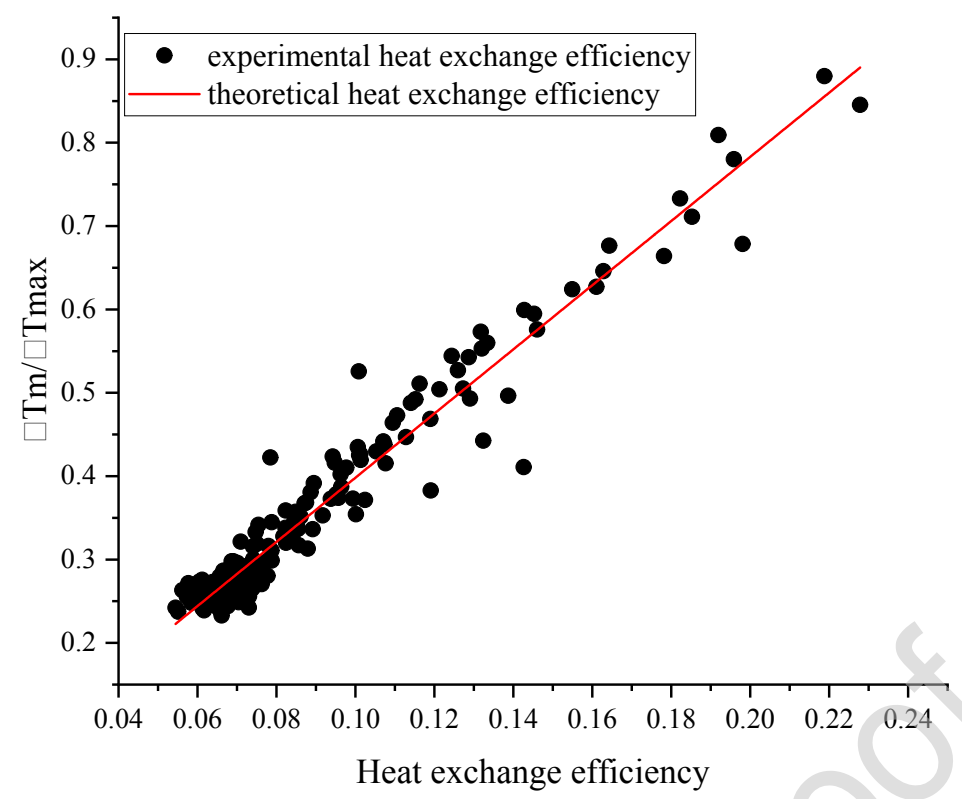

Fig. 19 The heat transfer efficiency of the conventional HSEU

The data comparison shown in Figs. 18 and 19 shows that the new HSEU has a much higher heat transfer efficiency than the conventional HSEU, by up to $70 \%$. This increased efficiency was achieved by two factors: (1) confined tank space and (2) formation of the counter-flow between the solar loop fluid and the heating loop fluid, which led to the increased convective heat transfer between the tank water and the coil wall.

\subsection{Comparison of the thermal efficiencies of the solar panel-arrays of the new and conventional systems}

The new HSEUs produced a significant difference in the temperature of the fluid at the inlet of the solar panel-array compared to the old HSEU, and consequently led to a considerable difference in solar thermal efficiency. Fig. 20 shows the experimental temperature data from inlet of the solar panel-array with the conventional and new HSEU. For the system with conventional $\mathrm{HSEU}$, the temperature increased gradually from $29^{\circ} \mathrm{C}$ to $50^{\circ} \mathrm{C}$ between $9: 30$ to 14:30 and then fell to $36^{\circ} \mathrm{C}$ by 17:00. For the system with the new HSEU, the intermittent operation of the submerged pump enabled the heat charge and discharge processes between the large and small tanks to take place using the dedicated control mechanism. This led to more frequent variation of the inlet temperature of the solar panel-array, which rose from $28^{\circ} \mathrm{C}$ to $36^{\circ} \mathrm{C}$ between $9: 30$ and $10: 30$, and fell to $33^{\circ} \mathrm{C}$ by $10: 40$. The temperature fall was caused by 
the starting the submerged pump. Similarly, the temperature rise from 15:30 to 15:40 was caused by switching off the submerged pump. The inlet temperature of the panel-array can directly influence the outlet temperature and the solar thermal efficiency. The variation in temperature of the solar arrays inlet and outlet are shown in Fig. 20 and Fig. 21 respectively.

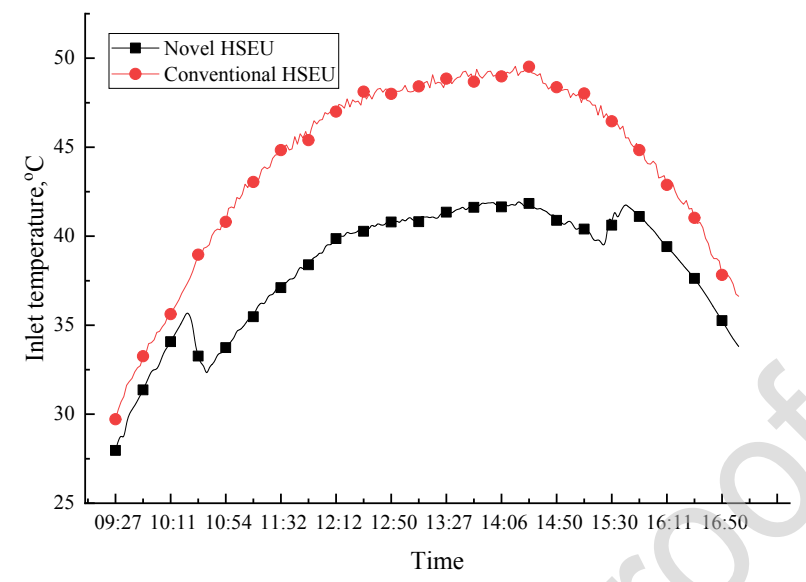

Fig. 20. The variation of the inlet temperature of the solar thermal array

Fig. 21 shows the experimental temperature data from the outlet of the solar panel-array. For the system with the conventional HSEU, the outlet temperature rose from $30^{\circ} \mathrm{C}$ to $58^{\circ} \mathrm{C}$ between 9:30 and $14: 30$ and fell from $58^{\circ} \mathrm{C}$ to $38^{\circ} \mathrm{C}$ between $14: 30$ and 17:00. For the system with the novel HSEU, the outlet temperature rose from $30^{\circ} \mathrm{C}$ to $43^{\circ} \mathrm{C}$ between 9:30 and 10:30, and fell to $40^{\circ} \mathrm{C}$ from $10: 30$ to $10: 40$. The temperature fall in the morning was caused by switching on the submerged pump. Similarly, the temperature rises from 15:30 to 15:40 was caused by the switching off the submerged pump. When the submerged pump was on, heat charge and discharge took place involving the mass exchange between the large and small tanks.

Comparison of the two systems indicates that the system with the new HSEU can achieve a more stable outlet temperature from the solar panel-array. Consequently, the temperature of the heating loop can be maintained at a more stable level. 


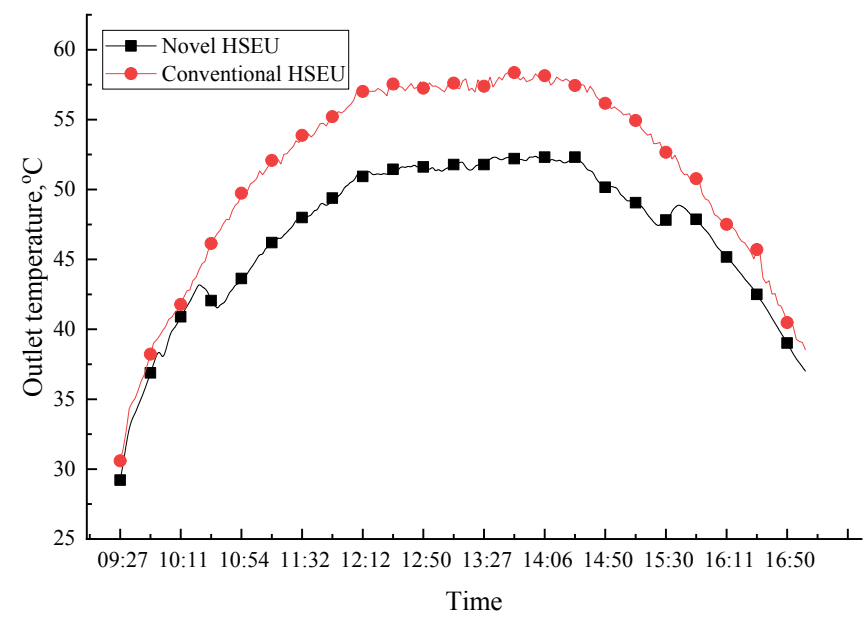

Fig. 21. The variation of the outlet temperature of the solar thermal array

Based on instant heat supply and solar radiation measurements, the hourly variation of the solar thermal efficiency of the panel-arrays was calculated and analyzed. The results for the novel and traditional HSEU's are shown in Fig.22. The system with the new HSEU achieved a higher solar thermal efficiency throughout daytime operation, relative to the system with the conventional HSEU. The reasons for this are: (1) Enhanced heat transfer coefficient of the new HSEU which resulted in a reduced return temperature for the solar loop fluid, enhancing the solar thermal efficiency of the panel-array; (2) Faster response to space heating and effective heat exchange between the small and large tanks, which resulted in reduced thermal resistance and an increased thermal conversion factor for the HSEU, increasing the solar thermal efficiency of the panels array. It is shown that during the morning hours between 9:00 and 10:30, both systems had a similar solar efficiency, due to relatively low solar radiation and solar loop fluid temperature, that in turn led to similar heat output to the tank water or heating loop fluid. The solar efficiencies of the two HSEUs remained almost constant from 12:30 to 13:30 and the solar efficiency of the novel HSEU was $14.7 \%$ higher than that of the conventional HSEU. During this same period, the average temperatures of the novel HSEU small tank and the conventional tank both equaled $43^{\circ} \mathrm{C}$, which means they had same space heating ability. However, due to the high convective heat transfer coefficient the novel HSEU was able to reduce the inlet temperature of solar thermal panel-array, thus giving a higher solar thermal efficiency. 


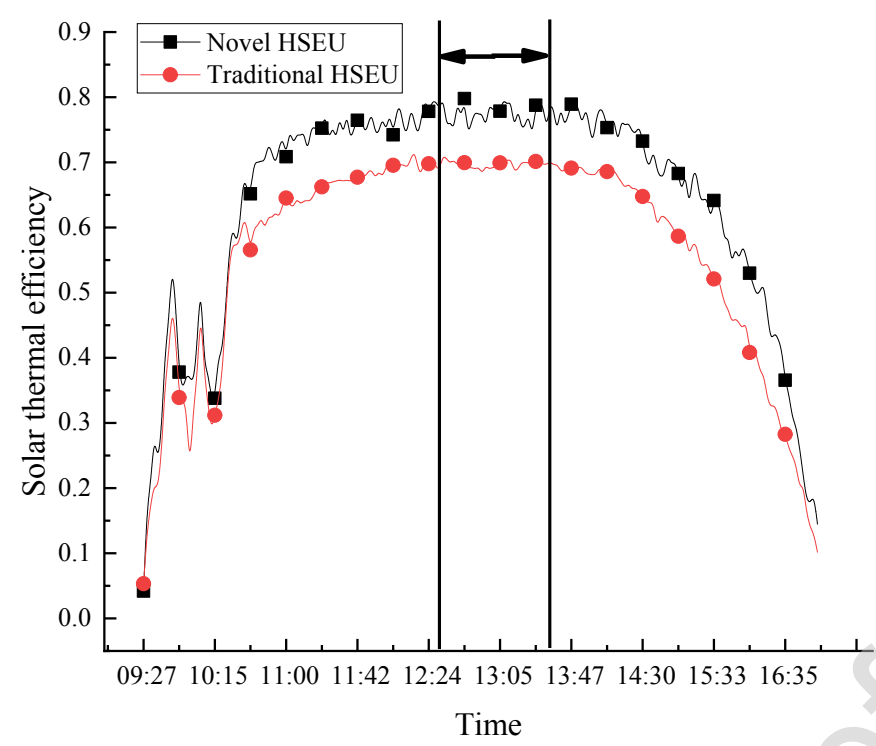

Fig. 22. The variation of the solar thermal efficiency of the solar thermal collector array with different HSEUs

\subsection{The heat charge and discharge processes of the new HSEU}

During daytime operation, when the heat supply from the solar panel-array is usually larger than the heat demand of the served space, the heat storage process takes place leading to the transfer of heat from the small tank to the large tank. In this case, the sub-merged pump was on from 10:30 to 15:30 which enabled the mass and heat transfer between the small and large tanks, resulting in the rise of temperature for the large tank from $35^{\circ} \mathrm{C}$ to $48^{\circ} \mathrm{C}$. The heat charge process for a typical day is shown in Fig. 23. To summarise, a total of $25 \mathrm{kWh}$ heat was charged into the large tank (1.5ton capacity) during day-time operation, this amount of heat was then discharged into the small tank during the evening and night, thus enabling an extended heating service time for the served space. 


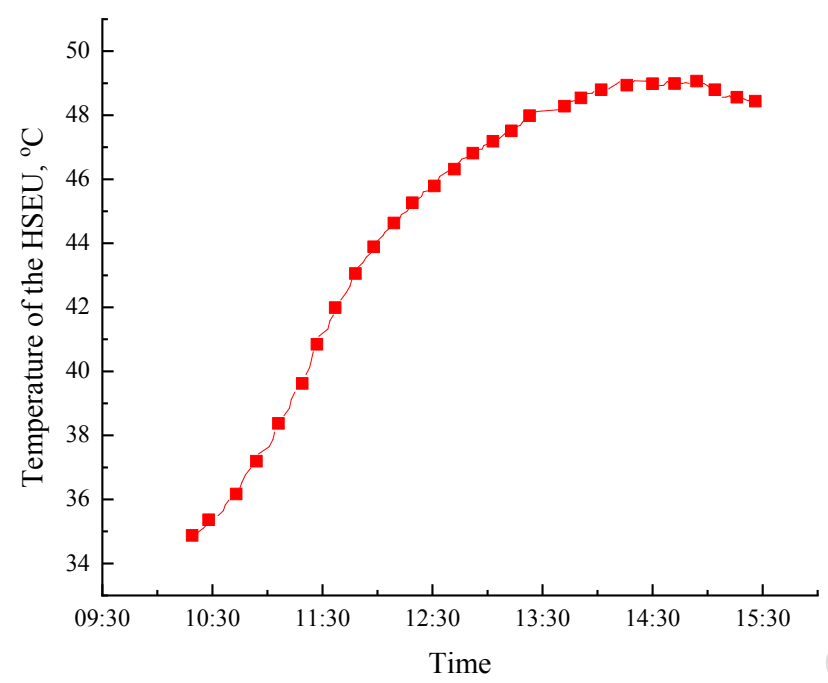

Fig. 23 The temperature variation of the heat storage tank

Fig. 24 shows the heat discharge process taking place between 16:30 and 03:00 the next day. The large tank experienced a minor temperature fall (from $48^{\circ} \mathrm{C}$ to $47^{\circ} \mathrm{C}$ ) during the period between 16:30 and 24:00, indicating that a small heat discharge process took place between the large tank and the small tank. During the period between 0:00 and 3:00, the large tank temperature fell from $47^{\circ} \mathrm{C}$ to $35^{\circ} \mathrm{C}$ indicating that a significant heat discharge took place. This resulted in a total of $20 \mathrm{kWh}$ heat being transferred to the heating loop fluid via the small tank, which enabled an extended heating service time to the served space.

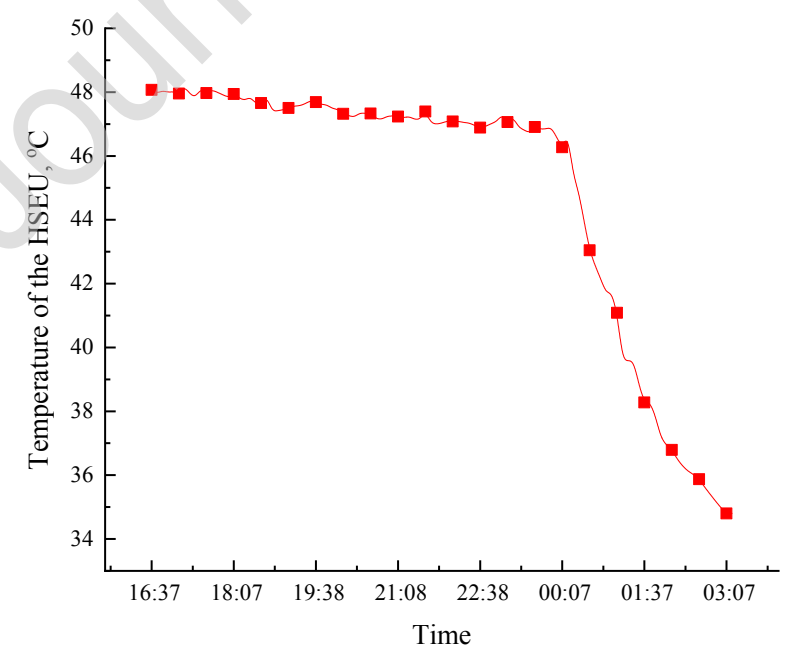

Fig. 24. Variation of the temperature of the heat storage tank during the night 


\section{Conclusions}

A novel interactive-double-tank-based heat storage/exchanging unit (HSEU) was developed to create a fast responsive solar heating system. This HSEU comprises a small heat exchange water tank and a large heat storage tank. The small tank is for fast thermal energy transfer to the heating loop fluid without the need to heat up the large volume of the water in the entire HSEU tank. The large heat storage tank is for charging and discharging heat into the small heat exchange tank, thus fulfilling the function of storing spare heat and releasing stored heat for space heating as required. In this paper we investigate the heat transfer between the solar loop and heating loop fluids, the heat and mass transfer between the small and larger tank fluids and the associated operational strategy, both experimentally and theoretically.

The interactive double-tank structure enables the novel HSEU based solar energy space heating system to respond to the heat demand of the served space in a faster and more energy efficient way. While a conventional HSEU is much slower to provide heating after sunrise, the system with the new HSEU can provide heating to the served space within approximately 20 minutes of sunrise. With a relatively low solar radiation level of 200 to $300 \mathrm{~W} / \mathrm{m}^{2}$, the system can deliver $40^{\circ} \mathrm{C}$ hot water to the heating loop system for the purpose of space heating. The analytical model developed by the authors achieved a good accuracy in predicting the performance of the HSEUs, giving a discrepancy of less than $10 \%$ compared to experimental results.

The new HSEU design can significantly increase the heat transfer effect. According to theoretical calculation, the new HSEU has a considerably higher heat transfer coefficient $\left(391 \mathrm{~W} / \mathrm{m}^{2} \cdot \mathrm{K}\right)$ compared to that of the conventional HSEU $\left(60.5 \mathrm{~W} / \mathrm{m}^{2} \cdot \mathrm{K}\right)$.

In addition, the novel HSEU led to an increase in solar thermal efficiency of the panelarray, due to a reduced temperature at the inlet of the solar panel-array. This leads to enhanced heat transfer between the solar loop and heating loop fluids and between the small and large tank water. Experimental Results showed an increase in the solar thermal efficiency for the panel-array of $7.5 \%$ under a solar radiation level of $500 \mathrm{~W} / \mathrm{m}^{2}$.

The capability of the novel HSEU to store the spare heat and maintain the room temperature was also investigated. During the day time the temperature of the HSEU increased from $35^{\circ} \mathrm{C}$ to $48^{\circ} \mathrm{C}$, thus storing $25 \mathrm{kWh}$ heat within the heat storage water tank. At 
night, when the room temperature reached the lower limit, the HSEU released the stored heat to maintain the room temperature, which indicates the HSEU can extend heating service time to the served space.

\section{Acknowledgements}

The authors would like to acknowledge our appreciation for the financial support received from the following projects: 'A low carbon heating system for existing public buildings employing a highly innovative multiple-throughout-flowing micro-channel solar-panel-array and a novel mixed indoor/outdoor air source heat pump' funded by the UK BEIS; 'A High Efficiency, Low Cost and Building Integrate-able Solar Photovoltaic/Thermal (PV/T) System for Space Heating, Hot Water and Power Supply' funded by Innovate UK and the UK Engineering and Physical Research Council (EP/R004684/1 - TSB 70507-481546); and 'Low Energy Dew Point Cooling for Computing Data Centres (DEW-COOL-4-CDC - 734340)' funded by EU H2020 Marie Curie International Research Staff Exchange Scheme programme.

\section{References}

[1] KEY CHINA ENERGY STATISTICS 2016

[2] Bertoldi Paolo, Diluiso F., Castellazzi L., Labanca N., Serrenho T. Energy Consumption and Energy Efficiency Trends in the EU-28 2000-2015, 2018.

[3] BP Statistical Review of World Energy 2017

[4] SD, Sagara K. Latent heat storage materials and systems: a review. International journal of green energy 2 (2005) $1-56$.

[5] Grazia Leonzio. Solar systems integrated with absorption heat pumps and thermal energy storages: state of art direct and indirect solar assisted heat pump system. Renewable and Sustainable Energy Reviews 70 (2017) 492-505

[6] Raghad S.Kamel, Alan S.Fung, Peter R.H.Dash. Solar systems and their integration with heat pumps: A review. Energy and Buildings 87 (2015) 395-412

[7] M. Mohanraj, Ye. Belyayev, S. Jayaraj, A. Kaltayev. Research and developments on solar assisted compression heat pump systems - A comprehensive review (Part-B: Applications). Renewable and Sustainable Energy Reviews 83 (2018) 124-155

[8] Yang, W., Zhang, H., Liang, X. Experimental performance evaluation and parametric study of a solar-ground source heat pump system operated in heating modes. Energy 149 (2018) 173-178 
[9] Zhu, N., Wang, J., Liu, L. Performance evaluation before and after solar seasonal storage coupled with ground source heat pump. Energy Conversion and Management 103 (2015) 924-933

[10] Jradi, M., Veje, C., Jørgensen, B.N. Performance analysis of a soil-based thermal energy storage system using solar-driven air-source heat pump for Danish buildings sector. Applied Thermal Engineering 114 (2017) 360-373

[11] Zhao, M., Gu, Z.L., Kang, W.B., Jin, L.W., Zhang, Q.L. Experimental investigation and feasibility analysis on a capillary radiant heating system based on solar and air source heat pump dual heat source. Applied Energy 185 (2017) 2094-2105

[12] Guo, X., Shu, H., Gao, J., Sun, Z., Xu, D. Volume design of the heat storage tank of solar assisted water-source heat pump space heating system. Procedia Engineering 205 (2017) 2691-2697

[13] Maria T. Plytaria, Christos Tzivanidis, Evangelos Bellos, Kimon A. Antonopoulos. Energetic investigation of solar assisted heat pump underfloor heating systems with and without phase change materials. Energy Conversion and Management 173 (2018) 626639

[14] Weeratunge, H., Narsilio, G., de Hoog, J., Dunstall, S., Halgamuge, S. Model predictive control for a solar assisted ground source heat pump system. Energy 152 (2018) 974-984

[15] Badescu V. Model of a solar-assisted heat-pump system for space heating integrating a thermal energy storage unit. Energy Build 34 (2002) 715-726.].

[16] Zhao CY, Wu ZG. Thermal property characterization of a low melting temperature ternary nitrate salt mixture for thermal energy storage systems. Solar Energy Materials and Solar Cells 95 (2011) 3341-3346

[17] Jo“rn Ruschenburg, Sebastian Herkel, Hans-Martin Henning. A statistical analysis on market-available solar thermal heat pump systems. Solar Energy 95 (2013) 79-89

[18] Ruschenburg, J., Herkel, S. A review of market-available solar thermal heat pump systems. A technical report of subtask A. IEA SHC Task 44/HPP Annex 382013.

[19] Lerch, W., Heinz, A., Heimrath, R. Direct use of solar energy as heat source for a heat pump in comparison to a conventional parallel solar air heat pump system. Energy and Buildings 100 (2015) 34-42

[20] Jonas, D., Frey, G., Theis, D. Simulation and performance analysis of combined parallel solar thermal and ground or air source heat pump systems. Solar Energy 150 (2017) 500511

[21] Frank, E., Haller, M., Herkel, S. \& Ruschenburg, J. 2010. Systematic Classification of 
Combined Solar Thermal and Heat Pump Systems. In: Proc. of the EuroSun 2010 Conference, Graz, Austria

[22] Taehoon Kim, Byung-Il Choi, Yong-Shik Han, Kyu Hyung Do. A comparative investigation of solar-assisted heat pumps with solar thermal collectors for a hot water supply system. Energy Conversion and Management 172 (2018) 472-484

[23] Johra, H., Filonenko, K., Heiselberg, P., Engelbrecht, K., Bahl, C. Integration of a magnetocaloric heat pump in an energy flexible residential building. Renewable Energy 136 (2019) 115-126

[24] Zhang, X., Liu, X., Chen, B., Zhao, J.R., Sang, Y. Numerical simulation of heat transfer process of the raised floor heating system integrated with a burning cave. Renewable Energy 132 (2019) 1104-1111

[25] Gavaldà L., Garcia-Nuñez M., Quero S., Gutierrez-Milla C., Sabrià M. Role of hot water temperature and water system use on Legionella control in a tertiary hospital: An 8-year longitudinal study. Water Research 149 (2019) 460-466

[26] Knapp, S., Nordell, B. Energy-efficient Legionella control that mimics nature and an opensource computational model to aid system design. Applied Thermal Engineering 127 (2017) 370-377

[27] R.H.S.Winterton. Thermal Design of Nuclear Reactors: CHAPTER 4 - ForcedConvection Heat Transfer. Great Britain, A. Wheaton \& Co. Ltd (1981) 38-66;

[28] B. R. Munson, D.F Young, T. H. Okiisshi. Fundamentals of Fluid Mechanics. John Wiley and Sons, Inc., (1998);

[29] Y. Nakayama, R.F. Boucher. Intoduction to Fluid Mechanics. Butterworth Heinemann, (1999);

[30] H.Schlichting. Boundary Layer Theory, 9th-edition. McGraw-Hlii (2016).

[31] Ephraim M. Sparrow. Advances in Heat Transfer, Vol.50. Elsevier Ltd. (2018).

[32] Fakheri, Ahmad. Heat Exchanger Efficiency. Journal of Heat Transfer. 129 (2007) 12681276 


\section{Declaration of interests}

$\bigotimes$ The authors declare that they have no known competing financial interests or personal relationships that could have appeared to influence the work reported in this paper.

$\square$ The authors declare the following financial interests/personal relationships which may be considered as potential competing interests:

There is no financial interests/personal relationships which may be considered as potential competing interests 
1. A novel fast-responsive heat storage/exchanging unit (HSEU) is proposed.

2. It is the first time a small tank for heat transfer is used in a large storage tank.

3. Experimental tests on the prototype have been conducted.

4. The HSEU can save 140 minutes for a temperature increment of $10^{\circ} \mathrm{C}$.

5. The concept of fast-responsive storage for solar heating systems is demonstrated. 